\title{
YouTube y coronavirus: análisis del consumo de vídeos sobre la pandemia COVID-19
}

\section{YouTube and coronavirus: analysis of video consumption on the COVID-19 pandemic}

Marta Gil Ramírez. Universidad de Málaga. España.

martagr@uma.es

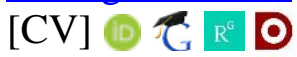

Ruth Gómez de Travesedo Rojas. Universidad de Málaga. España.

ruthgtr@uma.es

$[\mathrm{CV}] \odot \mathrm{R}^{\mathrm{T}} \mathrm{O}$

Ana Almansa Martínez. Universidad de Málaga. España.

anaalmansa@uma.es

$[\mathrm{CV}]\left(\mathrm{G} \mathrm{R}^{\mathrm{T}} \mathrm{O}\right.$

\section{Cómo citar este artículo / Referencia normalizada}

Gil, M.; Gómez de Traveseo, R. \& Almansa, A. (2020). YouTube y coronavirus: análisis del consumo de vídeos sobre la pandemia COVID-19. Revista Latina de Comunicación Social, 78, 121-153. https://www.doi.org/10.4185/RLCS-2020-1471

\section{RESUMEN}

Introducción: Esta investigación examina la tipología del consumo de los vídeos más reproducidos en YouTube en relación con las primeras etapas de la crisis del coronavirus en España, categorizando las temáticas que obtuvieron mayor interés, las fechas que registraron niveles de consumo más elevados, y la tipología de los uploaders que sirvieron como principales fuentes de información. Metodología: Desde una perspectiva cuantitativa-cualitativa, se realiza un análisis de contenido de los 200 vídeos con mayor impacto entre el 13 de marzo y el 13 de abril de 2020, en base a los descriptores coronavirus y COVID-19. Resultados: Los canales de medios de comunicación, tanto españoles como extranjeros, constituyeron las principales fuentes informativas sobre la situación de la pandemia. Los contenidos centrados en datos epidemiológicos, seguidos de la comunicación institucional, fueron los que despertaron mayor interés. El consumo de vídeos aumentó tras el decreto del Estado de Alarma, coincidiendo los picos con las prórrogas del mismo y con aquellos momentos en los que el número de contagios se dispara. Discusión y Conclusiones: YouTube está funcionando en la pandemia de la COVID-19 como plataforma depositaria de informaciones provenientes de los sistemas de medios convencionales. Resulta significativa la ausencia entre los principales uploader de la OMS como agencia internacional de salud referente en las decisiones adoptadas por la mayoría de los países afectados, lo que plantea una reflexión sobre la oportunidad del uso estratégico de YouTube como medio de difusión masiva durante situaciones de riesgo para la salud pública como lo es la crisis del coronavirus. 
PALABRAS CLAVE: Coronavirus; COVID-19; Pandemias; Medios de comunicación; YouTube; Estado de alarma; España.

\begin{abstract}
Introduction: This research examines the typology of the consumption of the most reproduced videos on YouTube in relation to the early stages of the coronavirus crisis in Spain, categorizing the topics that obtained the most interest, the dates that recorded higher levels of consumption, and the typology of the uploaders that served as the main sources of information. Methodology: From a quantitative-qualitative perspective, is performed a content analysis of the 200 videos with the greatest impact between March 13 and April 13, 2020, based on the descriptors coronavirus and COVID-19. Results: The mass media channels, both Spanish and foreign, were the main sources of information about the status of the pandemic. The content focused on epidemiological data, followed by institutional communication, aroused the greatest interest. The consumption of videos increased after the decree of the State of Alarm, coinciding the peaks with the extensions of the decree, and with those times when the number of infections soars. Discussion and Conclusions: YouTube is operating on the COVID-19 pandemic as a depository platform for information from conventional media systems. It is significant the absence among of the main uploaders of WHO as an international health agency reference in decisions taken by most affected countries, which raises a reflection on the opportunity of strategic use of YouTube as a means of mass dissemination during public health risk situations such as the coronavirus crisis.
\end{abstract}

KEYWORDS: Coronavirus; COVID-19; Pandemics; Media; YouTube; State of Alarm; Spain.

\title{
CONTENIDO
}

1. Introducción. 1.1. YouTube: divulgación de datos sobre la pandemia y filtraje de contenidos nocivos. 1.2. YouTube como fuente de información periodística. 2. Metodología. 3. Resultados. 4. Discusión y Conclusiones. 5. Bibliografía. 6. Currículum Vitae. 7. Anexos

\section{Introducción}

La crisis provocada por el virus SARS-CoV-2, mencionado generalmente como coronavirus, ha trastocado el habitual funcionamiento de todos los sectores sociales: salud, economía, política, comunicación, transporte, cultura, etc. Nada ha logrado escapar a la magnitud de la pandemia de la COVID-19, que ha sido la mayor en los dos últimos siglos si tenemos en cuenta el número de países y población afectados (Costa-Sánchez y López-García, 2020). El desconocimiento de tratamientos efectivos ante el nuevo patógeno, su alta tasa de contagio, su rápida propagación y su letalidad colocan a esta crisis sanitaria como un caso más complejo y con mayor repercusión respecto a crisis precedentes similares, como la del Ébola o la gripe A.

A pesar de tratarse de un problema de salud pública global, el coronavirus se ha desarrollado en forma y tiempos distintos en los territorios que se han visto aquejados. En España, el primer caso de coronavirus, en la isla de La Gomera, se dio a conocer el 31 de enero de 2020. Bien avanzado el mes de febrero, ya se habían detectados nuevos contagios puntuales en las Comunidades de Madrid, Cataluña y Valencia. El 11 de marzo, la Organización Mundial de la Salud (WHO, 2020) califica el brote epidémico como pandemia. Sin embargo, como causa probable de los mensajes institucionales que restaban importancia al riesgo y la posible incidencia de la enfermedad en las etapas más tempranas de la crisis (Costa-Sánchez y López-García, 2020), la población española en su conjunto no tomó conciencia real de la gravedad de la situación sanitaria hasta el 14 de marzo, fecha en la que el Gobierno decretó el Estado de Alarma (España, 2020) y a partir de la cual, el obligado 
confinamiento con carácter general (a expensas de las excepciones contempladas en la norma) marcó un antes y un después en lo que se ha venido a llamar la "normalidad" del país.

Entre los sectores concernidos por el coronavirus, el presente trabajo atiende al ámbito de la comunicación y concretamente a los cambios en los hábitos de consumo informativo que ha generado la insólita situación socio-sanitaria y la consiguiente cuarentena. Los medios de comunicación adquieren un protagonismo adicional en situaciones de crisis relacionadas con la salud (Westlund y Ghersetti, 2015) incrementando, como ha ocurrido en el caso de la pandemia de la COVID-19, su producción (Lázaro-Rodríguez y Herrera-Viedma, 2020) en respuesta al aumento significativo del interés ciudadano por la información (Casero-Ripollés, 2020), lo que altera de facto las cifras habituales de consumo mediático (Masip et al., 2020). En estas circunstancias, la información como principal fuente de conocimiento de lo que acontece tiene un efecto calmante sobre la ansiedad que genera lo desconocido, si bien, con un tratamiento inadecuado, puede contribuir a todo lo contrario generando o aumentando ese sentimiento de angustia o inquietud.

La relevancia del asunto para la salud pública, sumada a la paralización de la mayor parte de las actividades de la vida social y económica, han derivado en una cobertura mediática sin precedentes. La información relativa al coronavirus ha copado la mayoría de los contenidos en los medios tradicionales, que han experimentado grandes incrementos de audiencia $(A I M C, 2020)$ y ha inundado igualmente las publicaciones en portales digitales (Costa-Sánchez y López-García, 2020) y redes sociales.

Distintos estudios (Park, Boatwright y Johnson, 2019; Idoiaga-Mondragón, 2016) han identificado a la televisión y la prensa como medios de comunicación de referencia ante crisis sanitarias. También en el caso de la pandemia de la COVID-19 la televisión se demuestra como el medio de comunicación más consumido (Besalú, 2020; Casero-Ripollés, 2020). En concreto, dentro de la parrilla televisiva, los programas informativos han sido la primera opción de la ciudadanía para mantenerse informada sobre la evolución de la pandemia (Masip et al., 2020). Los medios tradicionales han actuado en esta crisis sanitaria como "medios refugios" (Xifra, 2020), como instituciones percibidas como confiables por parte de la ciudadanía. Por otra parte, ha sido igualmente constatado el importante papel desarrollado por los medios digitales (Lázaro-Rodríguez y Herrera-Viedma, 2020) y las redes sociales en el ámbito de la información concerniente al coronavirus (López-García, 2020), lo que reafirma la hibridación entre ambos sistemas mediáticos tradicional y digital- (Chadwick, 2013; López-Meri, Marcos-García y Casero-Ripollés, 2017; Masip et al., 2020) que tienden a complementarse (Takahashi, Tandoc y Carmichael, 2015) o retroalimentarse.

El insólito confinamiento de gran parte de la población mundial y el flujo informativo global característico de los nuevos medios digitales son dos de los factores que han contribuido al hecho de que podamos calificar a esta pandemia como la más mediática hasta la fecha, llegando incluso a generar un contexto de sobreexposición informativa (Casero-Ripollés, 2020; Masip et al., 2020), que en algunos casos, puede llegar a ser contraproducente (Garfin, Silver y Holman, 2020). La comunicación juega un papel crucial en esta crisis sanitaria, de ahí la importancia de atender estas peculiares circunstancias comunicativas desde el ámbito académico.

Esta investigación propone examinar las características de los vídeos más reproducidos en YouTube en las primeras etapas de la crisis del coronavirus en España, categorizando las temáticas que obtuvieron mayor interés, las fechas que registraron niveles de consumo más elevados, y finalmente determinando la tipología de los uploaders que sirvieron como principales fuentes de información. 


\subsection{YouTube: divulgación de datos sobre la pandemia y filtraje de contenidos nocivos}

YouTube se encuentra entre los sitios web más visitados por los usuarios españoles, solo superado por Google - propietario de la plataforma de vídeos_-, Facebook y Amazon; y por encima de los portales digitales de algunos de los principales medios de comunicación en España —El País o El Mundo-, así como de otras redes sociales como Twitter o Instagram (AIMC, 2020).

A pesar del carácter lúdico y los fines de entretenimiento por los que se caracteriza la plataforma de vídeos online, las búsquedas sobre materiales didácticos, divulgativos y noticias de actualidad son crecientes en esta red social, máxime en situaciones de crisis sanitarias como la que nos ocupa. Así lo atestiguan Orduña-Malea, Font-Julián y Ontalba-Ruipérez (2020) que identifican un considerable aumento del número de vídeos sobre COVID-19 en YouTube a partir del establecimiento del Estado de Alarma en España y una preponderante presencia de los canales de medios de comunicación nacionales como emisores de dichos contenidos. En relación al aumento del consumo en YouTube en las primeras etapas de la pandemia, estos mismos autores (Orduña-Malea et al., 2020) hacen referencia al estudio elaborado por la empresa 2btube (http://2btube.com) que constata un incremento del $55 \%$ en el número de reproducciones en la plataforma de vídeos procedentes del territorio español en la segunda quincena de marzo de 2020 respecto al mismo periodo en 2019.

El blog oficial de YouTube (https://youtube.googleblog.com/) recoge, en un post de la CEO Susan Wojcicki (11-06-2020), algunas de las principales iniciativas que la plataforma ha realizado en relación con la crisis del coronavirus:

- Una de las principales prioridades ha sido conectar a las personas con información confiable a medida que la pandemia se extendió por todo el mundo. Diferentes equipos han colaborado con funcionarios de salud pública en más de 90 países para que pudieran poner a disposición información relevante a nivel local que se muestra en la página de inicio y en paneles que aparecen en vídeos y en resultados de búsqueda sobre COVID-19. Colectivamente, estos paneles se han mostrado más de 200 mil millones de veces.

- Lanzamiento de una plataforma de noticias dedicadas al COVID-19, con vídeos de autoridades sanitarias y organizaciones de medios de comunicación, en más de 30 países de todo el mundo.

- Actuaciones para combatir la información médica nociva a través de consultas, de forma continua, con autoridades sanitarias como la Organización Mundial de la Salud, así como profesionales médicos y expertos de salud pública, para diseñar políticas basadas en los conocimientos científicos más recientes. A fecha 11 de junio de 2020, YouTube había eliminado más de 200 mil vídeos por violar sus políticas en cuanto a contenido engañoso o dañino relacionado con el coronavirus.

- Puesta en marcha de la campaña \#withme PSA, alentando a los usuarios a quedarse en casa y destacando mensajes importantes sobre cómo detener el virus, a la que se unieron más de 700 creadores y artistas de la comunidad YouTube.

Los altos incrementos en su consumo y la preeminencia de los medios de comunicación como emisores de contenido durante la pandemia de la COVID-19 sitúan a YouTube como una plataforma relevante en el estudio de los cambios en las dinámicas comunicativas experimentados durante esta crisis sanitaria. El análisis del consumo de información en esta red social, atendiendo a su amplia penetración, puede arrojar un diagnostico preliminar de los temas que más preocuparon o interesaron a los ciudadanos durante las primeras etapas del Estado de Alarma en España, así como a través de qué fuentes han obtenido información sobre el curso de la pandemia en el territorio nacional. 


\subsection{YouTube como fuente de información periodística}

Los contenidos generados por los medios de comunicación tradicionales siguen teniendo un peso importante en el consumo mediático ciudadano, pero los canales digitales mantienen una línea ascendente que invita a pensar en el progresivo protagonismo de estos, máxime si tenemos en cuenta el empleo que las nuevas generaciones — nativos digitales - realizan de herramientas como portátiles, tablets y smartphones para una conexión "casi permanente" a Internet.

En el ámbito español la audiencia de la televisión ha pasado de un 91,3\% en 1996 a un 85\% en 2018, la de los diarios decrece igualmente $(32,9 \%$ en $1996 ; 22,8 \%$ en 2018$)$, mientras que la de Internet, apenas inexistente en 1996 (1\%), se sitúa en un 82,1\% en 2018 (AIMC, 2019).

En este contexto, el auge en el uso de redes sociales es otro de los factores que ha incidido de manera directa en la transformación que viene experimentando el sistema mediático tradicional. La penetración de espacios como Facebook, Twitter o YouTube supone un fenómeno que se ha de tener en cuenta en la reconfiguración de las prácticas comunicativas.

Entre las redes sociales más populares YouTube es la que, por su carácter puramente audiovisual, más similitudes guarda con la televisión como medio de comunicación. No en vano, la plataforma de vídeos online ha sido definida como "la televisión post-moderna" (Murolo, 2010) o "el paradigma del vídeo y la televisión en la web" (Antolín-Prieto, 2012). Sin embargo, esta plataforma digital, como el conjunto de redes sociales, conlleva un componente social inédito y distintivo respecto del conjunto de los medios convencionales: la posibilidad de participación/intervención ciudadana en la producción y difusión de contenidos, una opción prácticamente inexistente en el ámbito mediático offline.

La "desintermediación" (Masip, Ruiz-Caballero y Suau, 2019) que propician las redes sociales, entre ellas YouTube, está en la base de su origen: lugares en los que la autonomía del usuario escapa a la intervención/interpretación del sistema mediático representativo. Desde esta perspectiva YouTube favorece un modelo de comunicación horizontal (Gil y Gómez de Travesedo, 2020) donde los usuarios auto-gestionan los mensajes que producen, consumen y difunden (Rodríguez-Serrano, García-Catalán y Martín-Nuñez, 2019) constituyéndose en un espacio que representa una genuina manifestación de la tendencia sociocultural hacia la auto-expresión y la participación (De Aguilera, Castro y Pérez-Rufí, 2018).

Desde el momento en que todos los medios utilizan un código común a la hora de producir sus contenidos digitales e Internet elimina la necesidad de un soporte material, haciendo accesible dicha producción sin límites de espacio o tiempo, el usuario establece nuevas reglas y condiciona a las industrias culturales a adaptarse a sus demandas. (Pérez-Rufi, 2012, p. 45)

Sin embargo, en los últimos años, diversos autores (Gallargo-Camacho, 2010; Gallardo-Paúls y Enguix-Oliver, 2016) comienzan a cuestionar la "mitificada horizontalidad" que se produce en la información que circula en las redes sociales que, más que como fuentes generadoras de nuevos contenidos, funcionarían como canales de difusión que redirigen tráfico a las webs de los diferentes medios convencionales, soslayando una jerarquización de emisores muy similar a la de la realidad mediática offline (Gallardo-Paúls y Enguix-Oliver, 2016).

En el caso concreto de YouTube, la mayor parte de las investigaciones que han abordado el peso que los medios de comunicación tradicionales tiene en la plataforma de vídeos apuntan hacia el concepto 
de "transmediación" (Berrocal, Campos y Redondo, 2012, 2014; Gil, 2019b). El mayor peso en la producción de los contenidos en dicha red recae sobre los ciudadanos particulares, pero la tendencia predominante es trasladar a la plataforma material generado en origen por los medios de comunicación de masas. Convergencia o hibridación (Uribe-Jongbloed, 2016) son otros de los términos que se emplean para describir la alianza o complementariedad que se ha establecido entre la plataforma de vídeos online y las empresas del tradicional sistema mediático.

En este sentido, España es uno de los principales países del entorno europeo en cuanto al volumen de medios de comunicación que usan YouTube para la difusión de contenidos audiovisuales. La mayoría de los medios tradicionales tienen presencia en la plataforma prácticamente desde su nacimiento en 2005 (Antena 3 y RTVE en 2006, La Sexta y COPE en 2007 o El País en 2008).

La alta visibilidad que esta red social proporciona a los medios convencionales podría estar entre los principales motivos que llevan a estos a estar presentes en esta plataforma de consumo masivo. En ella, los medios offline multiplican exponencialmente la difusión de sus contenidos y aumentan considerablemente su audiencia. A esto se suma el acceso a estadísticas y analíticas que YouTube pone a disposición de los medios tradicionales, algo que les puede resultar a posteriori de gran utilidad estratégica.

La industria mediática tradicional cuenta con herramientas de marketing que la posicionan en una situación ventajosa en relación a la producción audiovisual que en YouTube generan los usuarios comunes, y que contribuyen a situarla como el principal generador de los contenidos audiovisuales más consumidos en esta red social (Pérez-Rufi, 2012). El dominio de grandes agencias de comunicación es cada vez mayor en YouTube (Gil, 2019a), donde se ha constatado, por ejemplo, una contundente influencia de las cadenas de televisión generalistas españolas que ganan progresivamente peso y por tanto influencia en esta red social (Gallardo-Camacho, 2010) o estrategias específicas de SEO (search engine optimization) para un mejor posicionamiento de los vídeos de cibermedios españoles en esta plataforma (Lopezosa, Orduña-Malea y Pérez-Montoro 2020).

YouTube funcionaría así como contenedor de contenidos procedentes del sistema mediático tradicional, como una fuente secundaria de información periodística que aloja los mensajes producidos en origen por los medios convencionales —en sus versiones offline o digitales-.

En el caso que nos ocupa, el uso de YouTube como fuente de información sanitaria ya ha sido abordado en numerosas crisis precedentes a la pandemia de la COVID-19. Diversos estudios han analizado las características de las informaciones producidas y difundidas en la plataforma de vídeos online sobre el Ébola (C.H. Basch et al., 2015; Nagpal et al., 2015; Pathak et al., 2015), la Gripe A (Pandey et al., 2010; Walton, Seitz y Ragsdale, 2012), el virus Zika (C.H. Basch et al., 2017; Bora et al., 2018) o el virus del Nilo Occidental (Dubey et al., 2014).

La bibliografía científica que relaciona la crisis del coronavirus (SARS-CoV-2) y YouTube es aún incipiente, pero comienza a asentar algunas bases. Las principales coincidencias en las referencias existentes hasta el momento respaldan un aumento significativo del consumo de información en esta red social desde la declaración de la pandemia de la COVID-19 por parte de la OMS, así como una destacada presencia de agencias de noticias o medios de comunicación de masas entre los principales emisores de los contenidos más visualizados sobre el coronavirus (C.H. Basch et al., 2020; C.E. Basch et al., 2020; Khatri et al., 2020; Orduña-Malea et al., 2020). Si bien, del mismo modo, la literatura precedente presenta grandes diferencias con la presente propuesta que trata de sumar en la emergente línea de investigación que surge en torno al papel de YouTube en la actual crisis sanitaria 
generada por el coronavirus. Orduña-Malea et al. (2020) realizan un exhaustivo análisis métrico de más de 39.000 vídeos publicados y difundidos en YouTube sobre COVID-19 y relacionados directa o indirectamente con el territorio español. La delimitación geográfica resulta coincidente con la presente propuesta, pero nuestra investigación pretende un análisis más intensivo que extensivo a través de una perspectiva mixta que añade al examen cuantitativo la componente cualitativa. Por otra parte, los trabajos que adoptan, como el que se propone, este tipo de metodología - cuantitativacualitativa - sobre una muestra más reducida presentan algunas limitaciones que esta investigación trata de solventar. Khatri et al. (2020) trabajan sobre una muestra de 114 vídeos con la pretensión de analizar la calidad de la información disponible en YouTube sobre coronavirus, comparando el contenido publicado en inglés con aquel emitido en chino mandarín. Li et al. (2020) trabajan sobre 65 videos extraídos de búsquedas bajo las etiquetas "coronavirus" y "COVID-19", restringiendo la muestra a aquellos contenidos publicados únicamente en inglés y centrando la investigación en la presencia de contenidos engañosos o de dudosa calidad. Por otra parte, con el objetivo de determinar la cantidad de vídeos de YouTube que trasladaron alguno de los comportamientos de prevención recomendados por los Centros para el Control y la Prevención de Enfermedades de los EE.UU., C.H. Basch et al. (2020) proponen el examen de los 100 vídeos más vistos generados por el término de búsqueda "coronavirus" teniendo en cuenta, en relación al idioma de publicación del contenido, tanto el inglés como el español. Los resultados de este primer estudio (C.H. Basch et al., 2020), cuyo corpus se extrae el 31 de enero de 2020, son actualizados meses después (20 de marzo de 2020), dando como resultado una investigación (C. E. Basch et al., 2020) con la misma base metodológica pero con matices diferenciadores en los hallazgos.

El presente trabajo tiene como objetivo profundizar en el tipo de consumo que se ha realizado en YouTube sobre información relacionada tanto con el virus del "coronavirus" como con la enfermedad "COVID-19" y vinculada al territorio español, en las primeras etapas de la pandemia. Atendiendo a una muestra de 200 vídeos publicados tanto en inglés como en castellano, se propone un estudio pormenorizado de los temas que han centrado el interés de los usuarios, así como de los uploaders (emisores de contenidos) que han actuado como principales fuentes de información en relación con la evolución de la crisis sanitaria en España durante el primer mes del Estado de Alarma. La investigación se completa con un examen cronológico de los momentos que han generado mayores picos de consumo.

\section{Metodología}

La recopilación de la muestra se realiza a través del panel de búsquedas de YouTube.com. En un primer momento, se considera emplear los tres descriptores más populares y definitorios relacionados con la pandemia: "coronavirus" y "SARS-CoV-2" (en referencia al virus), y "COVID19" (en referencia a la enfermedad). Sin embargo, tras un tanteo preliminar de los vídeos resultantes del término de búsqueda "SARS-CoV-2", nos declinamos por prescindir de esta etiqueta dado que los contenidos obtenidos resultan excesivamente técnicos y vinculados al ámbito de la medicina, lo que se aleja de la pretensión de este estudio que busca una aproximación de carácter más sociológico. Así, finalmente se diseñó un sistema de búsqueda basado en query splitting (Orduña-Melea et al., 2020) en base a diversos componentes, con el propósito de obtener un mayor número de resultados.

- Componente 1 (virus): "coronavirus"

- Componente 2 (enfermedad): "COVID-19"

- Componente 3 (vinculación geográfica): "España"

Este último descriptor geográfico ("España") se combinó con los otros dos componentes con el fin de recopilar aquellos vídeos que trataban algún aspecto sobre la situación y/o evolución de la pandemia 
en el territorio nacional español. Dadas las diferencias en la incidencia, temporalización y gestión de la crisis sanitaria en los distintos territorios afectados, resulta preciso abordar, máxime en las fases iniciales, cada uno de ellos de forma independiente, al margen de la utilidad que futuras investigaciones, con la suficiente perspectiva, puedan aportar en el análisis global del suceso. España (a 15 de junio de 2020), se sitúa como el tercer país con mayor tasa de mortalidad (número de fallecidos por cada 100 mil habitantes) a causa de la COVID-19, solo superado por Bélgica y Reino Unido.

A los resultados obtenidos en ambas búsquedas ("coronavirus España" y "COVID-19 España") se le aplicaron dos de los filtros que posibilita YouTube: "fecha de subida: este mes" y "ordenar por: número de visualizaciones", atendiendo a los 100 primeros resultados en cada caso. La muestra se recoge el 13 de abril de 2020, con lo que el corpus obtenido responde a los vídeos más veces reproducidos durante la primera etapa de la crisis sanitaria (coincidiendo con el primer mes del Estado de Alarma en España) en relación tanto al virus como a la enfermedad que atañen a la pandemia.

En el transcurso de la investigación y de la revisión por parte de los diferentes codificadores (MG y RG) se descartan dos vídeos de entre los resultados arrojados por la etiqueta "COVID-19" por los siguientes motivos:

- El contenido del vídeo, emitido desde el mismo canal, se duplica en una versión traducida al español $^{1}$. En este caso de deja en la muestra la versión en inglés del vídeo, atendiendo a su mayor número de reproducciones ${ }^{2}$.

- El contenido del vídeo está duplicado ya que ha sido emitido desde dos canales distintos. En este caso, de nuevo se mantiene en la muestra el vídeo que obtiene mayor número de reproducciones ${ }^{3}$.

Entre los 198 vídeos que resultan finalmente entre ambas búsquedas, encontramos 16 contenidos duplicados (con idéntico idioma y canal de procedencia). Una vez eliminados, la muestra global queda configurada por 182 vídeos.

\footnotetext{
${ }^{1} \mathrm{https}: / / \mathrm{www}$. youtube.com/watch?v=cF23RKyoANo

2 https://www.youtube.com/watch?v=_J60fQr0GWo

3 https://www.youtube.com/watch?v=uAT8EEKBySM (se mantiene en la muestra), https://www.youtube.com/watch?v=p6tvOgkI03c (se elimina de la muestra).
} 


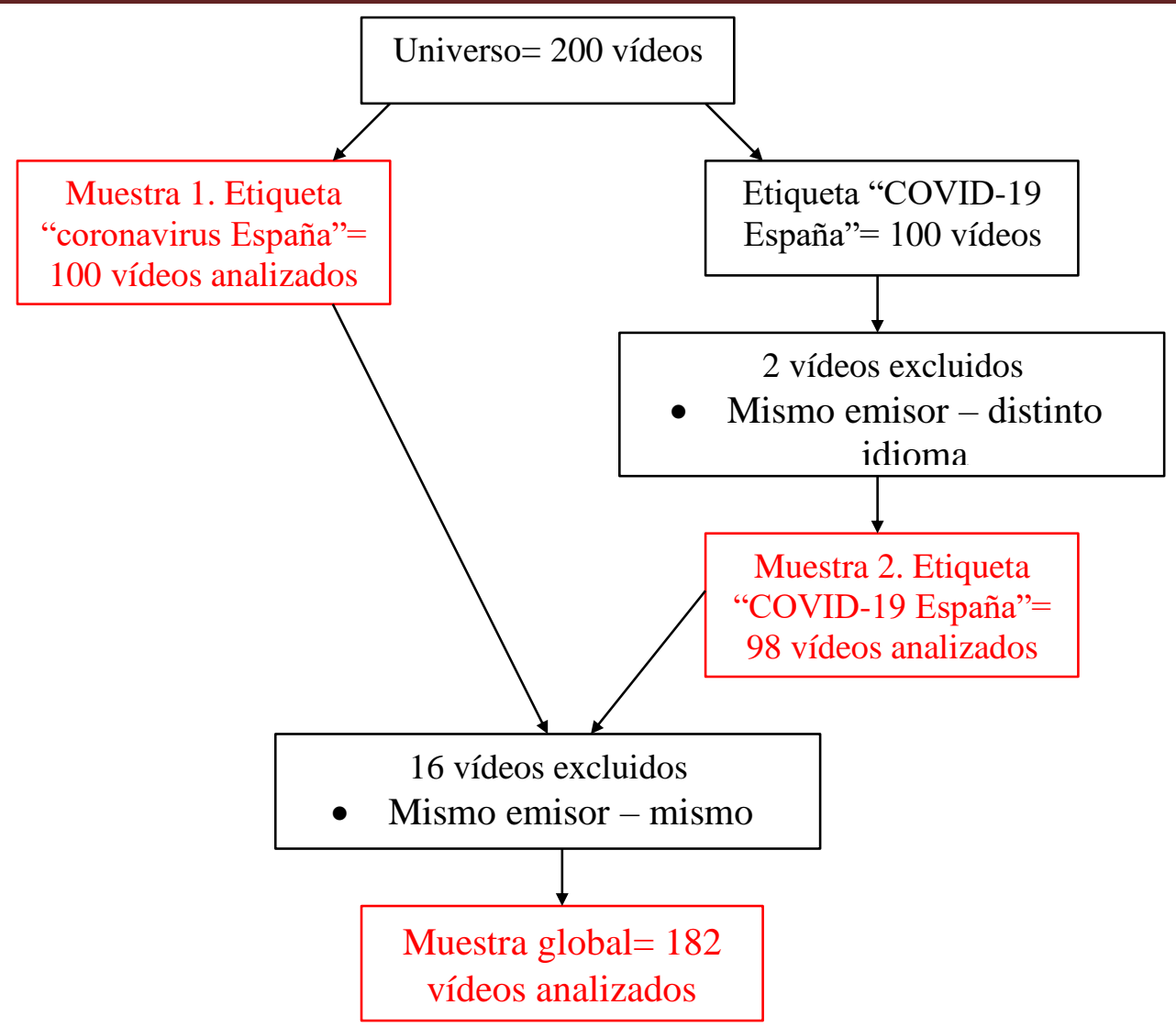

Figura 1: Proceso de construcción de las muestras 1-2 y global.

Fuente: elaboración propia.

Esta investigación propone realizar un análisis desde dos perspectivas distintas: por un lado, atendiendo a la muestra global $(\mathrm{n}=182)$ y por otro, estableciendo una comparativa entre los resultados obtenidos a través de las dos etiquetas de búsqueda empleadas: "coronavirus España" (n= 100) y "COVID-19 España" ( $\mathrm{n}=98)$. Esta comparativa supone una novedad frente a los estudios precedentes y permitirá comprobar los matices que se producen en el consumo de información en YouTube en función de que el contenido se refiera al virus o a la enfermedad.

Los hipervínculos de cada uno de los vídeos fueron recopilados en una hoja de cálculo para su posterior cotejo y consulta. El contenido de la muestra global $(n=182)$ que ha supuesto la visualización de más de 116 horas de audiovisual, resulta superior al examinado en estudios de diseño metodológico similar, relacionados con vídeos sobre coronavirus o COVID-19 en YouTube (C.H. Basch et al., 2020; C.E. Basch 2020; Khatri et al., 2020; Li et al., 2020).

Para la recogida y codificación de los datos se confecciona una ficha de análisis que incluye las principales características descriptivas de cada contenido: título, número de reproducciones, fecha de subida y duración; así como una serie de categorías que tratan de dar respuesta a las siguientes preguntas de investigación:

- ¿Cuáles son las fuentes de la información más consumida en YouTube en base a los descriptores “coronavirus España” y "COVID-19 España”? La clasificación de las variables que se proponen como opciones de respuesta - Medios de comunicación, Usuarios comunes, Partidos políticos u Otros - se fundamentan en la validez constatada en estudios previos que han abordado la identidad digital del emisor de contenidos en YouTube: en relación con la pandemia de la COVID-19 (C.H. 
Basch et al., 2020; C.E. Basch 2020; Khatri et al., 2020; Li et al., 2020; Orduña-Malea et al., 2020) $\mathrm{o}$, antes de la crisis sanitaria, vinculados al estudio de la comunicación política en la plataforma social (Berrocal et al., 2012; Berrocal, Gil y Campos, 2016; Berrocal, Martín y Gil, 2017; Gil, 2019a, 2019b; Gil, Gómez de Travesedo y Almansa, 2019; Gil y Gómez de Travesedo, 2020).

- ¿Cuáles son los temas sobre los que versan los vídeos más consumidos en YouTube en base a los descriptores "coronavirus España" y "COVID-19 España"? A pesar de que los descriptores propuestos ya constituyen una temática en sí mismos, se consideró interesante establecer subcategorías que aportaran información más detallada sobre las cuestiones específicas que han despertado mayor interés entre los usuarios en torno a la crisis sanitaria. En este sentido, la literatura previa no dispone de herramientas de evaluación validadas, por lo que se propone (tabla 1) un instrumento específico con 12 variables temáticas.

Tabla 1. Instrumento de análisis temático

\begin{tabular}{|c|c|c|}
\hline CATEGORÍA & VARIABLES & DESCRIPCIÓN \\
\hline \multirow{3}{*}{$\begin{array}{l}\text { Información } \\
\text { sanitaria }\end{array}$} & $\begin{array}{l}\text { Información Epidemiológica } \\
\text { (a excepción de la proveniente } \\
\text { del Gobierno) }\end{array}$ & $\begin{array}{l}\text { Cifras sobre contagios, fallecidos, recuperados, } \\
\text { análisis de la evolución de la pandemia, datos } \\
\text { sobre la situación de hospitales, funerarias, etc. }\end{array}$ \\
\hline & Testimonios & $\begin{array}{l}\text { De sanitarios, virólogos, biólogos, expertos, etc. } \\
\text { o de particulares }\end{array}$ \\
\hline & \multicolumn{2}{|c|}{$\begin{array}{l}\text { Información relativa a la investigación sobre fármacos/tratamientos y/o vacuna } \\
\text { frente al coronavirus }\end{array}$} \\
\hline \multirow{4}{*}{ Comunicación institucional* } & \multicolumn{2}{|c|}{$\begin{array}{l}\text { Fragmento de rueda de prensa del Comité de Gestión Técnica del Coronavirus: } \\
\text { exclusivamente datos epidemiológicos }\end{array}$} \\
\hline & \multicolumn{2}{|c|}{ Rueda de prensa íntegra del Comité de Gestión Técnica del Coronavirus } \\
\hline & \multicolumn{2}{|c|}{ Comparecencias del Presidente del Gobierno } \\
\hline & \multicolumn{2}{|l|}{ Otros (Comunicación institucional) } \\
\hline \multicolumn{3}{|l|}{ Crítica política } \\
\hline \multicolumn{3}{|c|}{ Información relativa a la evolución de las medidas restrictivas que impone el Estado de Alarma y/o sanciones } \\
\hline \multicolumn{3}{|c|}{ Información económica y/o datos sobre el empleo } \\
\hline \multicolumn{3}{|c|}{ Información relacionada con el ámbito jurídico } \\
\hline \multicolumn{3}{|l|}{ Otros } \\
\hline \multicolumn{3}{|c|}{$\begin{array}{l}\text { * Comunicación institucional: nos referimos a aquella información procedente de alguno de los portavoces designados } \\
\text { por el Gobierno para trasladar a la ciudadanía detalles sobre cualquier aspecto relacionado con la pandemia y el } \\
\text { consiguiente Estado de Alarma. Pese a contener, en muchas ocasiones, información de índole sanitaria, el protagonismo } \\
\text { adquirido por el Gobierno dada la centralidad bajo el Mando Único que impone el Estado de Alarma, confiere al análisis } \\
\text { diferenciado de esta categoría un interés adicional. }\end{array}$} \\
\hline
\end{tabular}

Fuente: elaboración propia.

- ¿Cuáles son las fechas que han motivado un mayor consumo de información vinculada al territorio español en YouTube durante las primeras etapas de la crisis del coronavirus? ¿Guardan relación con algún hecho u acontecimiento socio-sanitario o político relevante? El análisis de la evolución del consumo de información sobre la pandemia de la COVID-19 a nivel cronológico y referido al territorio español es contemplado en estudios precedentes, bien en relación con la propia plataforma de vídeos online (Orduña-Malea et al., 2020), bien en relación con medios digitales españoles (Lázaro-Rodríguez y Herrera-Viedma, 2020).

Dos codificadores (MG y RG) revisaron y analizaron cada uno de los contenidos componentes de la muestra. Se empleó el coeficiente kappa de Cohen para evaluar el nivel de concordancia, resultando $\mathrm{k}=0,87$. 


\section{Resultados}

En el momento de la recopilación de los datos (13 de abril de 2020), los vídeos de la muestra ( $\mathrm{n}=$ 182) acumulaban un total de 113.336 .735 millones de reproducciones. El número medio de visualizaciones por vídeo fue de 622.729 mil. Sin descontar las duplicaciones, la muestra referida a "COVID-19 España" ( $\mathrm{n}=98)$ superó en más de 20 millones de reproducciones $(82.121 .567$; media= 837.975) a los contenidos que se desprendieron de la búsqueda "coronavirus España" $(\mathrm{n}=100)$ (61.666.143; media=616.661). El consumo de información sobre la evolución de la pandemia en las primeras etapas y relacionado con el territorio español ha estado, por tanto, más representado por el término COVID-19 que por el vocablo referido al virus (coronavirus).

En términos globales, entre los 74 emisores detectados, los canales de medios de comunicación han funcionado como uploaders mayoritarios $(64,86 \%)$, es decir como principal fuente de información sobre la crisis sanitaria, acaparando el $82,76 \%$ del contenido publicado. Las cuentas de medios de comunicación extranjeros desde las que se suben vídeos relacionados con la pandemia en España son más numerosas $(52,70 \%)$ que aquellas de medios nacionales $(12,16 \%)$. Sin embargo, estos últimos se muestran más activos, publicando una media de 2,76 vídeos por cada medio frente a los 0,93 contenidos de media que proceden de algún sistema mediático distinto al español. Entre los medios nacionales destaca la actividad de El País, El Mundo y La Vanguardia, mientras que entre los extranjeros, la participación de tres medios de ámbito europeo, DW News (Alemania), Sky News (Reino Unido) y Euronews (Francia) resulta la más significativa.

Los usuarios comunes actúan como uploaders en un 27,03\% de las ocasiones, siendo proporcional la relación entre aquellos en cuya ubicación consta España y aquellos con una localización diferente. Por otro lado, son mayoritarios aquellos usuarios que mantiene su anonimato (15,97\%), es decir, que no aportan información sobre su identidad en su cuenta de YouTube; frente a aquellos que sí lo hacen $(11,06 \%)$. En general, son usuarios que, atendiendo al número de suscriptores (199.412 de media), podrían considerarse youtubers. El nivel de actividad de esta tipología de uploaders en los contenidos relacionados con la evolución de la pandemia en España es muy leve, con una publicación media de 0,45 vídeos por usuario.

La participación de la esfera política en la emisión de contenidos en YouTube en las primeras etapas de la pandemia en España resulta prácticamente anecdótica, siendo Vox el único partido político que sube contenido que logre un número significativo de visualizaciones en la plataforma de vídeos online.

Un conjunto reducido de los uploaders $(6,76 \%)$ no corresponde con ninguna de las tipologías anteriores. Entre estos emisores encontramos a la compañía discográfica Warner Music Spain o al productor musical Alejandro Abad (alejandroabadmusic) entre otros. El porcentaje de contenido publicado desde este tipo de canales en el conjunto de la muestra $(3,56 \%)$ no resulta representativo. 
RLCS, Revista Latina de Comunicación Social, 78, 121-153

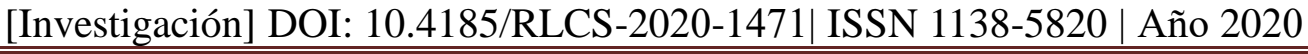

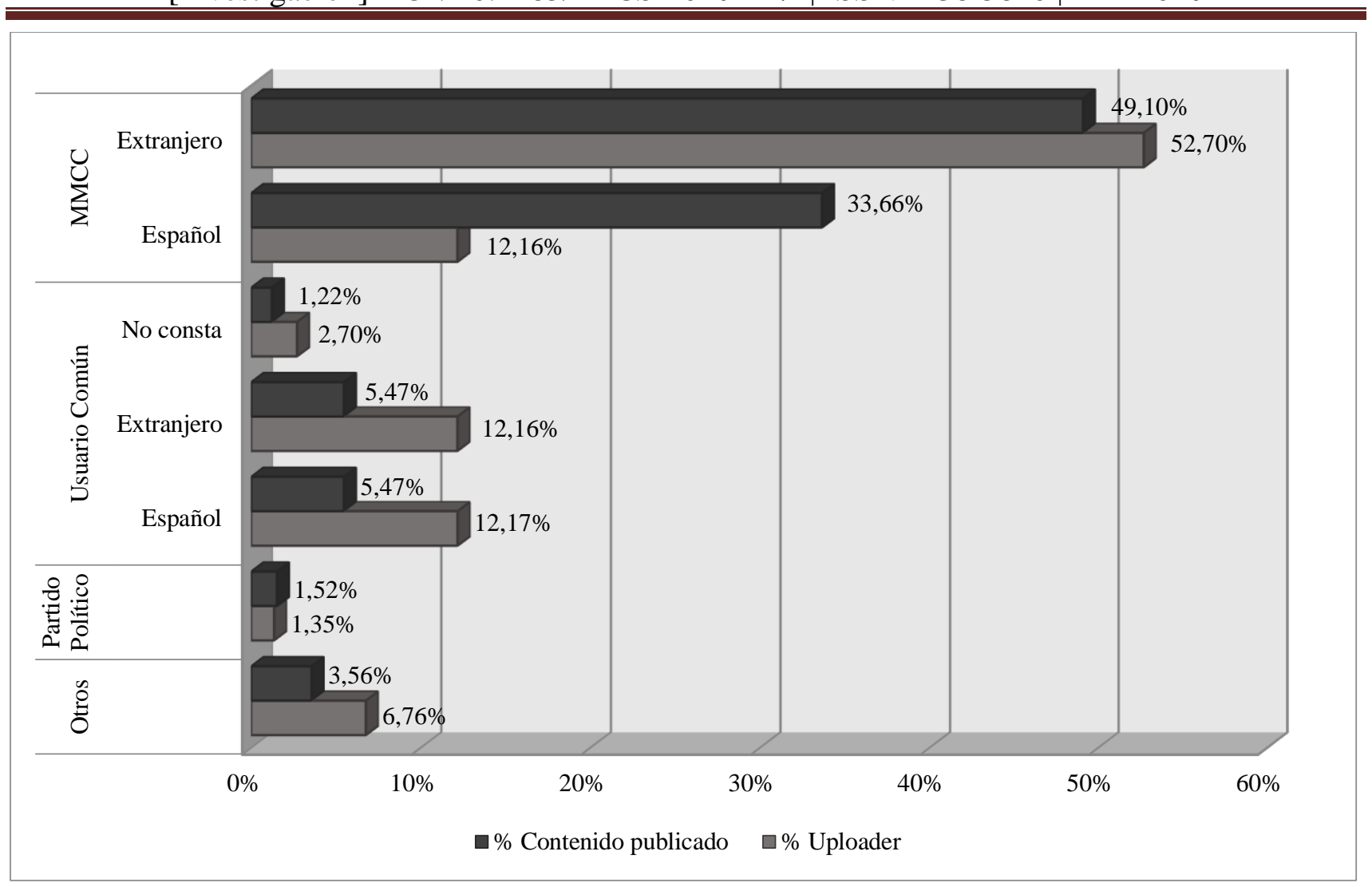

Gráfico 1: Tipología de uploaders y nivel de actividad en la publicación de contenido.

Fuente: elaboración propia.

En relación con el idioma de publicación de los vídeos más consumidos sobre la evolución de la pandemia en España, prevalece el español $(78,02 \%)$ frente al inglés $(21,98 \%)$.

Por otra parte, atendiendo a la comparativa entre las muestras individuales que se desprenden de las búsquedas "coronavirus España" (muestra 1: $\mathrm{n}=100$ ) y "COVID-19 España" (muestra 2: $\mathrm{n}=98$ ) (Ver Anexo 1), se evidencia una presencia y actividad de los medios de comunicación españoles mucho más destacada en la muestra 1, definida por los términos "coronavirus España", que en la muestra 2 bajo la etiqueta "COVID-19 España". En el primer caso, los medios nacionales representan cerca del $20 \%$ de los emisores y acaparan más de la mitad del contenido publicado; mientras que en el segundo, el porcentaje de medios nacionales que publica contenido desciende al 9,26\% y decae igualmente el número de vídeos que este tipo de emisores sube a YouTube (15\%) y se posicionan entre los más visionados. Los medios de comunicación extranjeros presentan cifras similares en su rol de fuentes de información en ambas muestras, pero destaca su actividad publicando contenidos en relación a la etiqueta "COVID-19 España" (60\%), frente a la desarrollada en la etiqueta "coronavirus España" (38\%). Existe un 3\% y un $9 \%$ de coincidencia de medios de comunicación españoles y medios de comunicación extranjeros respectivamente entre ambas etiquetas.

Los usuarios comunes españoles están más representados que los extranjeros en la muestra 1, tanto en cantidad como en contenido publicado. Respecto a esta tipología, en la muestra 2 los porcentajes están equilibrados. Existe un $2 \%$ de coincidencia en usuarios comunes españoles entre ambas muestras.

La presencia y actividad de otros emisores diferentes a medios de comunicación, usuarios comunes o partidos políticos es significativamente mayor en los vídeos resultantes de la búsqueda "COVID-19 
España”, en la que, en términos generales, el número y la variedad de emisores (54) es superior a la que presentan los contenidos que se desprenden de la búsqueda "coronavirus España" (36).

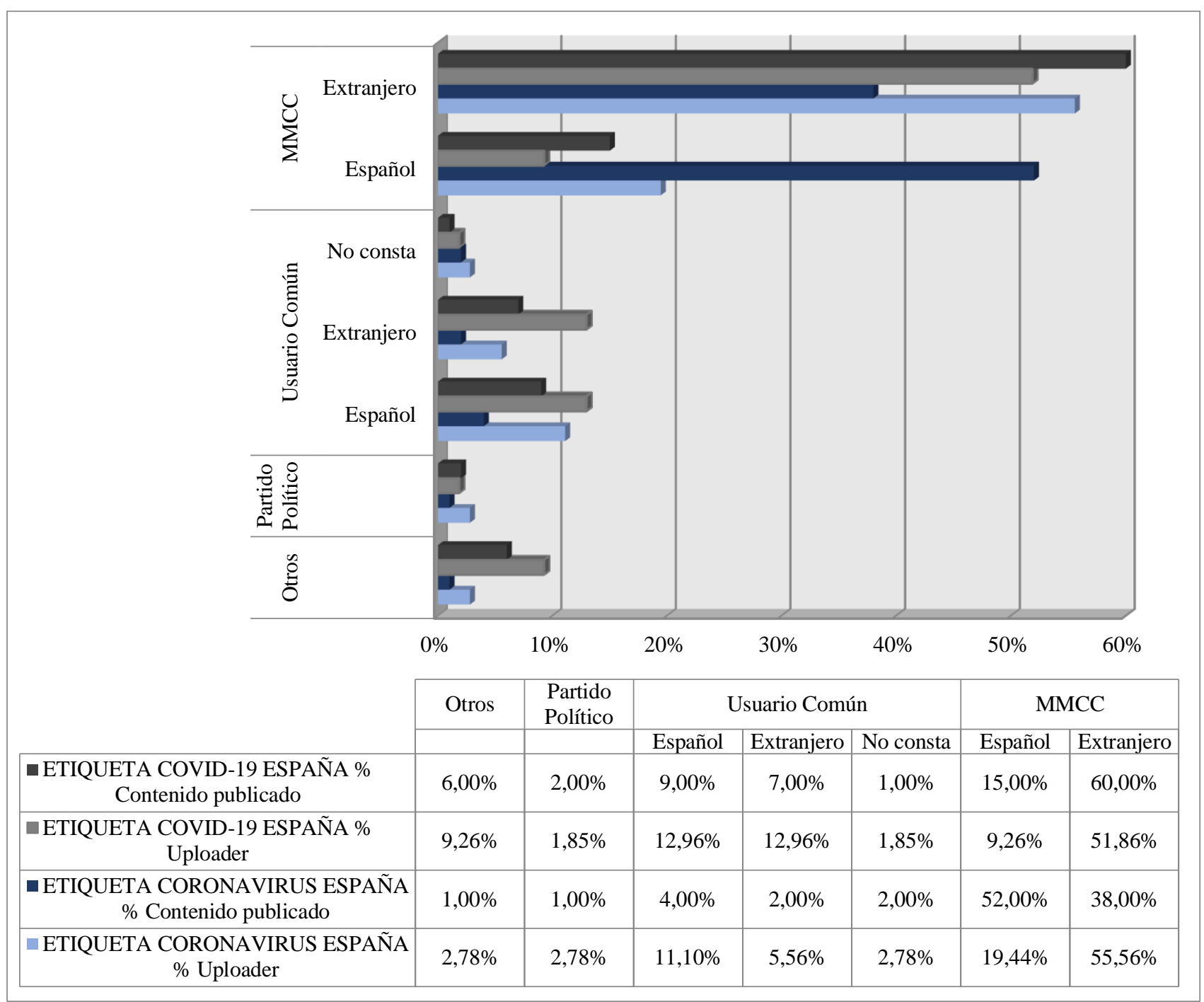

Gráfico 2: Comparativa tipología de uploaders y nivel de actividad en la publicación de contenido en función de la etiqueta de búsqueda empleada.

Fuente: elaboración propia.

Entre las temáticas de los vídeos con mayor impacto sobre la situación o evolución de las primeras etapas de la crisis sanitaria en España, destaca la información puramente sanitaria que no procede de fuentes gubernamentales $(38,94 \%)$. En concreto, la información epidemiológica es la más consumida en términos globales. El contenido de los vídeos que se engloban en esta categoría ofrece principalmente cifras sobre el número de contagiados y fallecidos, así como datos sobre la situación hospitalaria. Los testimonios, que se reparten a partes iguales entre aquellos que protagonizan expertos o personal sanitario y aquellos que narran las vivencias de particulares, no se encuentran entre las temáticas que despiertan mayor interés, quedando su presencia representada por un escaso 7,02\%. Tampoco, en las etapas iniciales que se analizan, los usuarios de YouTube prestan especial atención a las informaciones que, de forma aun temprana, comienzan a aparecer sobre posibles tratamientos ante la COVID-19 o la vacuna contra el virus. 
Por otra parte, lo que hemos denominado Comunicación Institucional, es decir, aquella que procede de algunas de las voces autorizadas por el Gobierno para informar sobre cualquier aspecto relacionado con la pandemia, acapara casi un cuarto $(22,59 \%)$ de entre las temáticas que abordan los vídeos que obtiene mayores índices de consumo en relación con el asunto. Los usuarios de YouTube visualizaron en similar porcentaje, por un lado fragmentos de la rueda de prensa ofrecida diariamente por los miembros del Comité de Gestión Técnica del Coronavirus, en los que como responsables del Área del Centro de Coordinación de Alertas y Emergencias Sanitarias del Ministerio de Sanidad, bien Fernando Simón o en su ausencia María José Sierra, aportaban las cifras epidemiológicas de la jornada; y por otro, vídeos que posibilitaban ver de forma íntegra la rueda de prensa de dicho comité y en los que, además de las cifras sobre la evolución de la pandemia, se actualizaba la información relativa a la actuación de los Cuerpos y Fuerzas de Seguridad del Estado, así como la referida al ámbito del transporte y la movilidad. Las comparecencias del presidente del Gobierno, Pedro Sánchez, despiertan un interés menor entre los usuarios de la plataforma que buscan información sobre la situación de la crisis sanitaria en España.

La crítica política, focalizada principalmente hacia la gestión de la pandemia por parte del Gobierno de coalición (PSOE- Unidas Podemos) no es, en las etapas iniciales, un tema cuyo consumo sea recurrente. Tampoco resulta significativo el interés de los usuarios hacia aquellos vídeos que trasladan información sobre las medidas restrictivas que impone el Estado de Alarma o las sanciones que conlleva su incumplimiento. La preocupación por la situación económica, que como a día de hoy (junio 2020) se constata se va acrecentado a medida que avanza la desescalada, no despierta prácticamente interés entre los consumidores de vídeos en YouTube en las primeras etapas de la emergencia sanitaria. La información de ámbito jurídico es inexistente.

En ocasiones $(9,62 \%)$ el contenido combina la información puramente sanitaria que no procede de fuentes gubernamentales con alguna otra temática, mayoritariamente con la relacionada con medidas restrictivas y/o sanciones. Del mismo modo, algunos de los vídeos $(8,10 \%)$ que se posicionan entre los más consumidos sobre el coronavirus o la COVID-19 en el territorio español, se corresponden con programas de larga duración (programas informativos completos, emisiones en directo de varias horas que son subidas posteriormente a YouTube, documentales, etc.) que abarcan más de dos de las tipologías temáticas propuestas. Por último, un $8,60 \%$ de los contenidos reflejan un consumo temático que, aunque relacionados con la situación de la pandemia en España, abordan la misma desde otras perspectivas como la música, el humor, las teorías conspiratorias o aspectos puramente anecdóticos. 


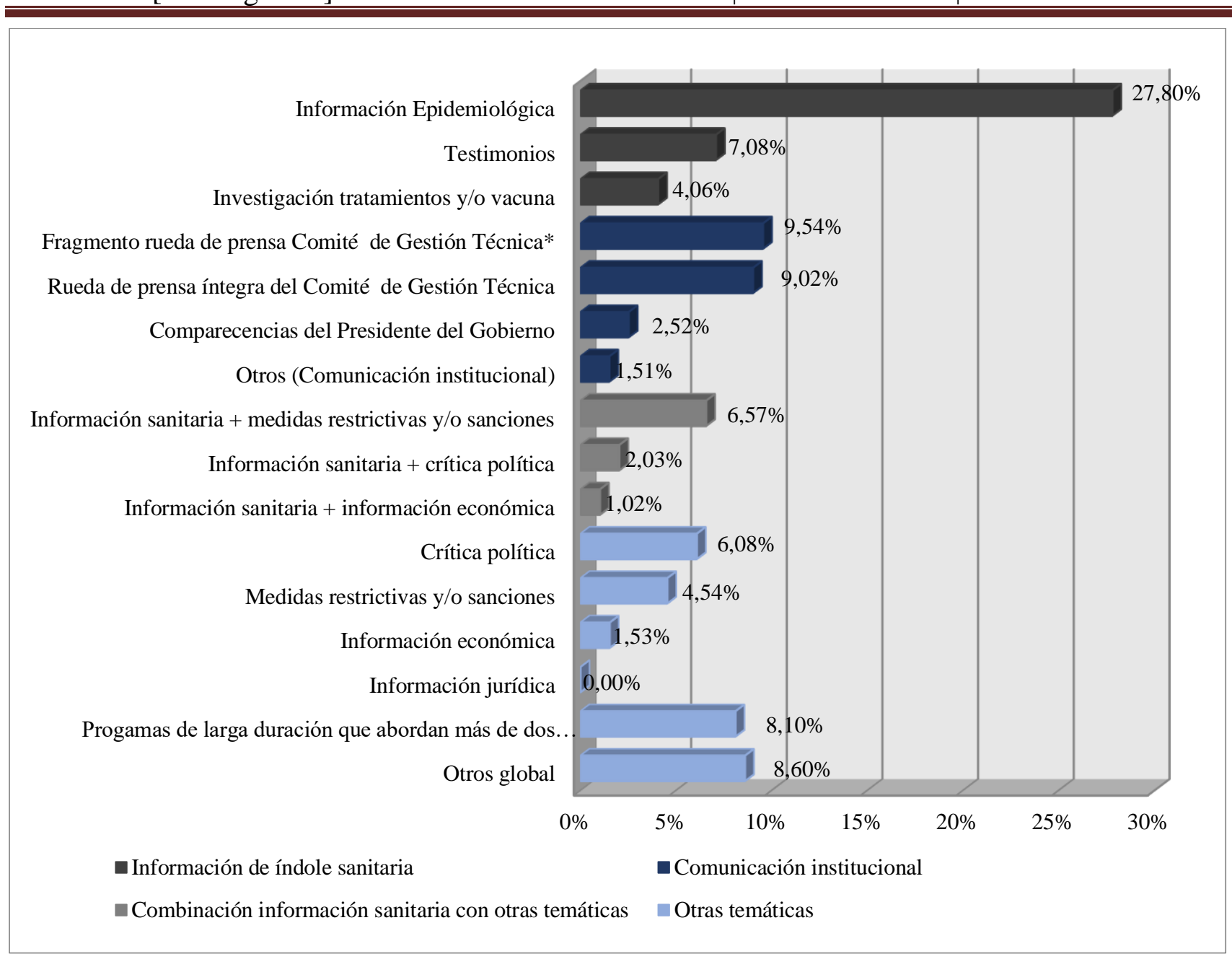

Gráfico 3: Clasificación temática. *Exclusivamente datos epidemiológicos.

Fuente: elaboración propia.

Si comparamos las temáticas más consumidas en función de los términos de búsqueda empleados (Ver Anexo 2) se observa un matiz diferenciador significativo. Los usuarios que acudieron a YouTube para informarse sobre la situación de la pandemia en España empleando el término "coronavirus" consumieron de forma mayoritaria contenidos centrados en la Comunicación Institucional procedente del Gobierno (36\%), una temática que pasa sin embargo desapercibida $(9,18 \%)$ cuando la etiqueta de búsqueda propuesta es "COVID-19 España". Los vídeos que se desprenden de esta última etiqueta giran principalmente en torno a información de índole sanitaria que no procede de fuentes gubernamentales $(43,88 \%)$. Destaca también en esta muestra (COVID-19 España) la presencia incipiente de contenidos que abordan información económica $(3,06 \%)$, una temática ausente en los vídeos generados por el descriptor "Coronavirus España", así como un mayor consumo de audiovisuales focalizados en la crítica política (8,17\% para COVID-19 España, frente a 4\% para coronavirus España), programas de larga duración que abordan temáticas variadas (10,20\% para COVID-19 España, frente a 6\% para coronavirus España) o contenidos que tratan la crisis de salud pública de una forma más cercana al entretenimiento que a la información $(9,18 \%$ para COVID-19 España, frente a 8\% para coronavirus España).

Destaca el hecho de que, pese a la preponderancia en términos generales de información de índole sanitaria y contenido centrado en la Comunicación Institucional del Gobierno, el vídeo más consumido en ambas etiquetas es Resistiré 2020, una canción producida por Warner Music Spain e interpretada por más de 30 artistas confinados en sus hogares. En el momento del análisis (13 de 
abril de 2020) este audiovisual acumula 16 millones de reproducciones, muy por encima de los 3,7 millones que recoge el segundo contenido más visualizado bajo el término "coronavirus España" y a cierta distancia de los 11 millones que aglutina el vídeo que ocupa el segundo lugar en cuanto a consumo en la etiqueta "COVID-19 España".

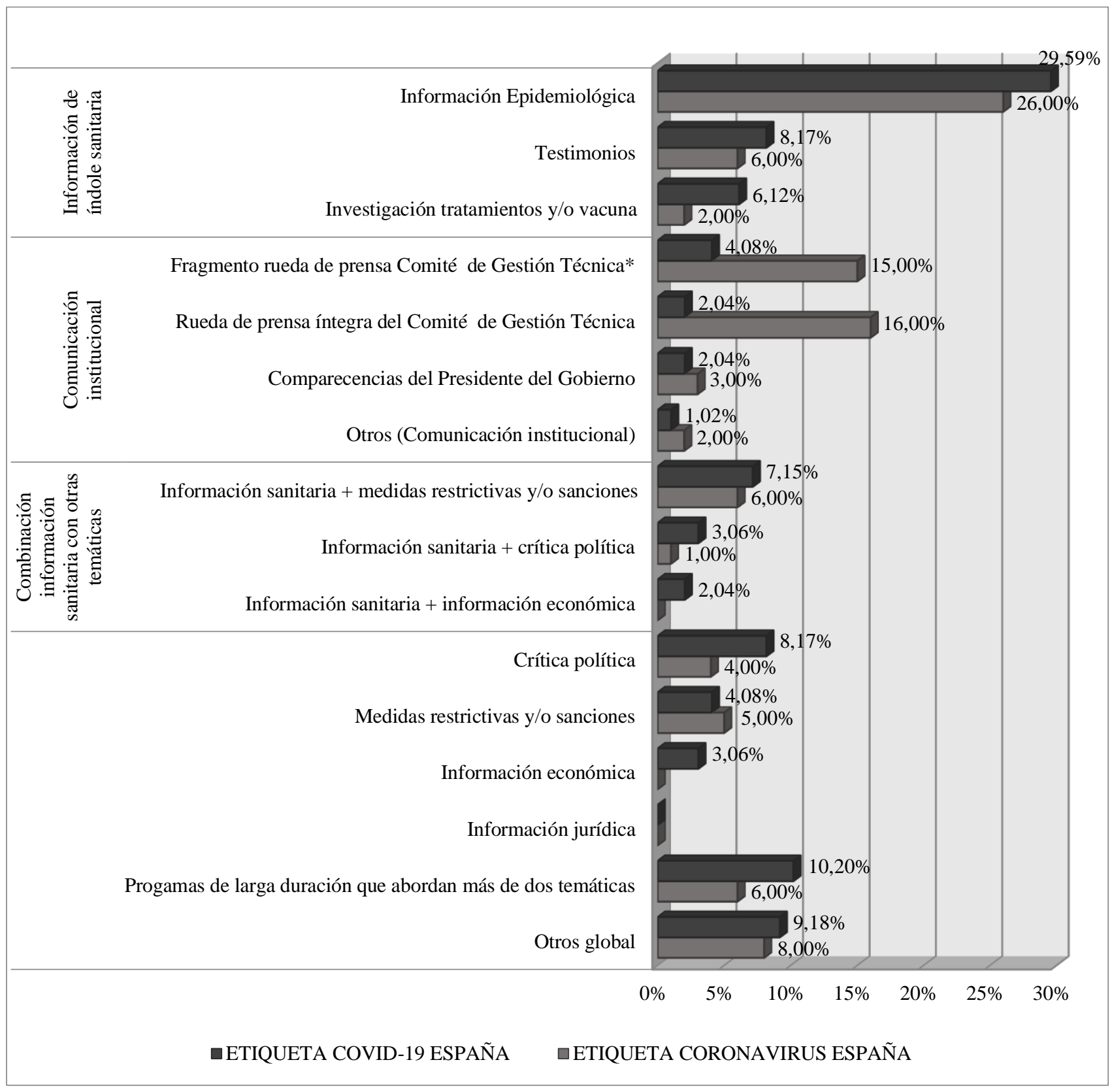

Gráfico 4: Comparativa clasificación temática en función de la etiqueta de búsqueda empleada. *Exclusivamente datos epidemiológicos.

Fuente: elaboración propia.

El cruce de los datos obtenidos en el análisis de los uploaders que funcionan como principales fuentes de información con las temáticas en los vídeos más consumidos durante las primeras etapas de la crisis sanitaria en España (Ver Anexo 3), sitúa a los medios de comunicación españoles como emisores destacados en los contenidos más visionados relacionados con la Comunicación Institucional procedente del Gobierno, fundamentalmente aquellos que reproducen de forma íntegra o parcial alguna de las ruedas de prensa que diariamente ofrecía el Comité de Gestión Técnica del 
Coronavirus (31\%). En relación con los medios de comunicación extranjeros, estos funcionan como fuente de información principalmente en los vídeos con mayor impacto que trasladan datos epidemiológicos sobre el desarrollo de la emergencia sanitaria en el contexto español (46,49\%). La actividad de los usuarios comunes como emisores de los contenidos sobre la pandemia que finalmente alcanzan mejores niveles de consumo está muy repartida a nivel temático entre la información epidemiológica (3,06\%), los testimonios $(3,07 \%)$, la crítica política $(3,07 \%)$ y otras temáticas $(7,08 \%)$, destacando esta última que da cuenta de contenidos menos trascendentales (musicales, memes, anécdotas, etc.) en relación con la crisis global de salud pública. El único partido político (Vox) que logra posicionar contenido entre el más reproducido sobre la situación de la pandemia en España, transpone en el mismo la crítica política de la formación hacia la gestión del Gobierno de coalición PSOE-Unidas Podemos de la crisis sanitaria. 
RLCS, Revista Latina de Comunicación Social, 78, 121-153

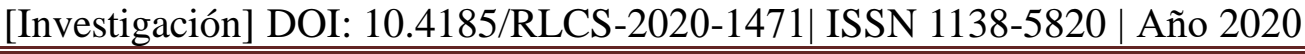

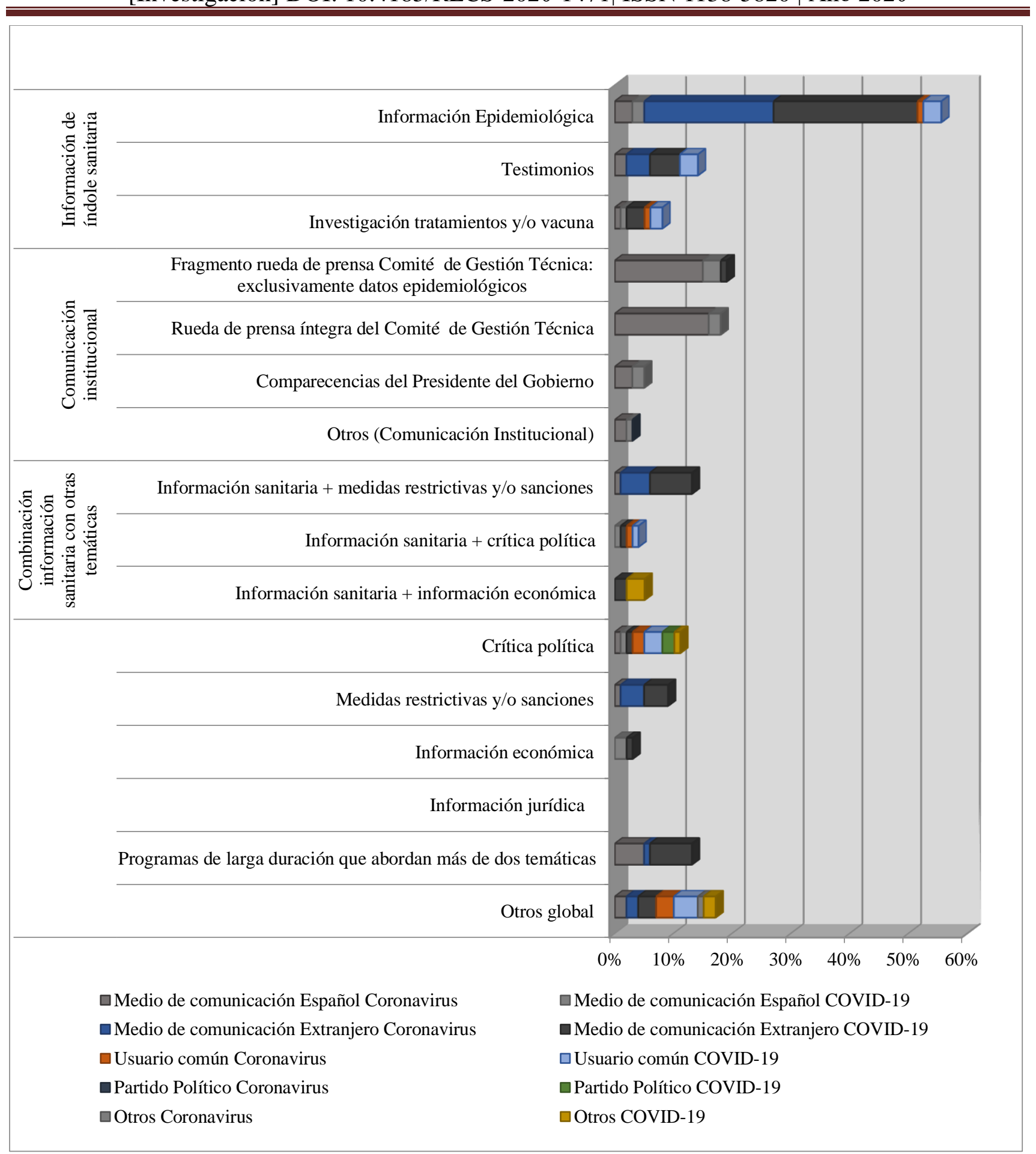

Gráfico 5: Cruce de variables uploaders/temática.

Fuente: elaboración propia.

El gráfico 6 muestra la cronología del consumo de vídeos en YouTube en base a las búsquedas "coronavirus España" y "COVID-19 España", así como el global resultado de ambas del 13 de marzo al 13 de abril, fecha que coincide con las primeras etapas de la pandemia en el territorio español y con el primer mes del Estado de Alarma decretado. Se observan coincidencias en un mayor número de vídeos publicados en momentos relevantes relacionados con la propia situación sanitaria (la aceleración del número de contagios en Europa o el pico en España), así como con la gestión de la misma a nivel gubernamental (Decreto del Estado de Alarma y las sucesivas prórrogas). 
RLCS, Revista Latina de Comunicación Social, 78, 121-153

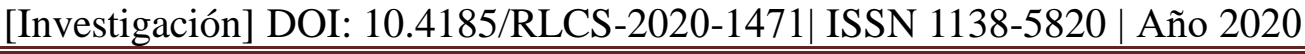

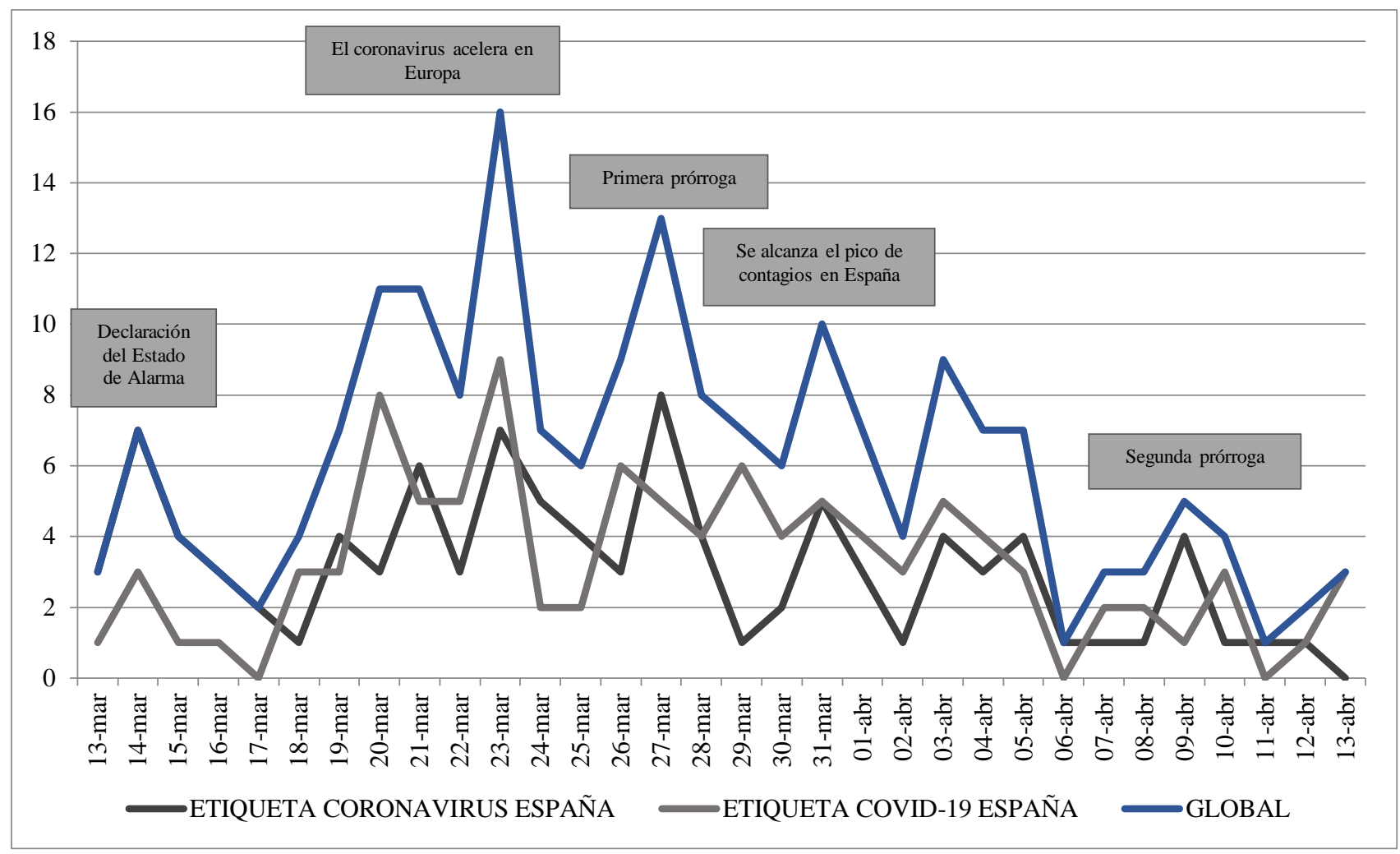

Gráfico 6: Evolución en el consumo de los vídeos publicados en YouTube sobre "coronavirus" o "COVID-19" (13 de marzo-13 de abril 2020).

Fuente: elaboración propia.

En cuanto a la evolución del consumo, se aprecian leves matices diferenciadores según los contenidos publicados correspondan con un descriptor de búsqueda u otro. Repartiendo el período de análisis en 4 bloques de 8 días, los términos "coronavirus España" generan entre los vídeos más consumidos un mayor número de publicaciones en el primer y segundo bloque, decayendo de forma progresiva entre el tercero y cuarto. Los audiovisuales más reproducidos en base a la etiqueta "COVID-19 España" sin embargo, son publicados mayoritariamente entre el segundo y tercer bloque, descendiendo de forma más acusada en el cuarto.

\section{Discusión y Conclusiones}

Los resultados de la investigación deben considerarse en el contexto de los descriptores de búsqueda propuestos, tanto los relacionados con la pandemia (Coronavirus y COVID-19) como el relativo a la delimitación geográfica (España), así como en el espacio temporal que se aborda (vídeos publicados entre el 13 de marzo y el 13 de abril de 2020). Se trata por tanto de un estudio transversal que refleja la tendencia sobre el consumo de vídeos en YouTube relacionados con la situación de la crisis sanitaria a nivel nacional en un momento concreto: las primeras etapas de confinamiento a partir del Estado de Alarma decretado por el Gobierno español. El carácter dinámico de la plataforma de vídeos online confiere gran volatilidad a este tipo de análisis, dado que las cifras de visionados en esta red social cambian constantemente. Es muy plausible que a medida que avanza la crisis de salud pública evolucionen igualmente los términos y las temáticas más recurrentes en torno a ella, y que los vídeos examinados se vean superados en número de reproducciones por nuevos contenidos. Sin embargo, cualquier trabajo que implemente este tipo de estrategias de búsqueda en YouTube 
conlleva esta limitación. Por ello, los hallazgos que se desprenden de la presente propuesta se circunscriben a los términos que la delimitan, siendo necesarios nuevos estudios que la complementen abordando períodos relacionados con la pandemia COVID-19 en sus distintas fases, así como en otras redes sociales u otras plataformas de compartición de vídeos.

El ámbito geográfico al que se refiere el análisis — España—, solo abordado hasta el momento por Orduña-Malea et al. (2020), pretende contribuir a dilucidar las peculiares características comunicativas que han tenido lugar en la plataforma de vídeos online como consecuencia de la particular incidencia, temporalización y gestión de la crisis sanitaria en el territorio español. Estas circunstancias han sido diferentes en función de la idiosincrasia del país afectado, por lo que abordar cada uno de ellos de forma independiente, especialmente en las fases iniciales, resulta de interés, al margen de la utilidad que futuras investigaciones, con mayor perspectiva, puedan aportar en el análisis global del suceso.

Pese a estos condicionantes, las posibilidades de YouTube para trasladar información sobre la crisis del coronavirus dado su alcance (millones de personas diarias), le confieren al análisis de este medio de difusión masiva una gran utilidad a la hora de conocer los comportamientos de consumo relacionados con la pandemia. La investigación ofrece una panorámica de la tendencia social en cuanto a las fuentes a través de las que se informaron los usuarios de esta red social o las temáticas que mayor interés despertaron en las fases tempranas de la emergencia sanitaria, en relación a España.

YouTube ha funcionado, en el caso analizado, como plataforma depositaria de informaciones provenientes de los sistemas de medios convencionales. Consolidadas marcas mediáticas, tanto españolas como de origen extranjero, han copado las publicaciones más visionadas sobre coronavirus y COVID-19 vinculadas al territorio español. Este hecho puede entenderse desde una doble perspectiva: como resultado de la posición referencial que la ciudadanía ha otorgado a los medios tradicionales (Xifra, 2020) y especialmente a los programas informativos (Masip et al., 2020) durante esta pandemia, o como consecuencia de las estrategias de SEO que los medios, en sus versiones digitales, aplican para un mejor posicionamiento de sus contenidos en YouTube (Lopezosa et al, 2020) incorporando términos relacionados con la pandemia en el título, la descripción o los comentarios de los vídeos y aprovechando de este modo el impulso de las consultas relacionadas con la crisis del coronavirus en la plataforma social (Orduña-Malea et al., 2020).

En consonancia con estudios precedentes (C.H. Basch et al., 2020; C.E. Basch et al., 2020; Khatri et al., 2020; Orduña-Malea et al., 2020) los canales de medios de comunicación han funcionado como uploaders mayoritarios en detrimento de las publicaciones subidas a YouTube desde cuentas de usuarios comunes. Tanto medios de comunicación españoles como extranjeros han sido fuentes de información destacadas sobre la situación de la pandemia en España. Entre los primeros, sobresale la actividad en la plataforma de vídeos de El País, El Mundo y La Vanguardia, tres medios presentes en el ranking que Orduña-Malea et al. (2020) elaboran sobre los canales con mayor número de vídeos publicados sobre COVID-19, en base a un análisis métrico de una muestra de más de 39 mil videos. En el caso de los medios extranjeros, también hallamos una coincidencia con dicho ranking en relación a Euronews en español, que junto a Dw News y Sky News resultan los canales más activos. Pese a la delimitación geográfica propuesta — España-, el alcance de YouTube y la dimensión global de la crisis, arrojan en este análisis una destacada incidencia de las publicaciones de medios extranjeros en el consumo de información sobre la situación de la pandemia en el territorio español. En este sentido, Costa-Sánchez y López-García (2020) apuntan a un interés intensivo por parte de la prensa internacional durante el primer mes desde la declaración de la emergencia de salud pública en España. 
La alta presencia de medios extranjeros no se vincula, sin embargo, con un predominio de vídeos publicados en inglés. Muchos de estos medios con sede fuera de España, emplean sus versiones en español cuando trasladan a esta red social información relativa al territorio nacional o bien utilizan directamente el español como idioma vehicular, como es el caso de los medios latinoamericanos. La prevalencia del español como idioma entre las publicaciones relacionadas con la situación de la pandemia en España resulta coincidente con los hallazgos de Orduña-Malea et al. (2020) y discrepantes con los de C.H. Basch et al., (2020) y C.E. Basch et al., (2020) que hallan el inglés como idioma predominante. Esta diferencia se explica a través del componente geográfico (España) que tanto esta propuesta como la de Orduña-Malea et al. (2020) incorporan a las búsquedas que determinan la muestra.

En las primeras etapas de la pandemia en relación al territorio español, la información procedente de canales de YouTube titularidad de partidos políticos, no despierta el interés de los usuarios de esta red social, ni siquiera aquella procedente del partido mayoritario en el Gobierno y con mayor peso en la gestión de la crisis sanitaria (PSOE) pese a contener la cuenta de este partido (https://www.youtube.com/user/psoe/videos) numerosos contenidos relacionados con la incidencia de la pandemia en España y a pesar de las importantes implicaciones sobre la comunicación de los gobiernos que ha conllevado la gestión de esta insólita situación (Rojo-Martínez y Soler-Contreras, 2020). Tan solo Vox logra una representación minoritaria a través del consumo de sus publicaciones, probablemente como resultado de la constatada eficacia de las estrategias narrativas implementadas por esta formación en la plataforma de vídeos online (Rodríguez-Serrano et al., 2019).

Resulta también significativa la ausencia como uploader, entre los vídeos más consumidos en torno a la crisis de salud pública generada por el coronavirus, de la OMS como agencia internacional de salud referente en las decisiones adoptadas por la mayoría de los países afectados y protagonista en gran parte de las informaciones transmitidas por los medios de comunicación convencionales en las primeras fases de la pandemia. Este hecho podría encontrar explicación en la poca actividad del canal de la OMS (https://www.youtube.com/channel/UC07-dOwgzalIguKA86jqxNA) con algo más de 580 mil suscriptores y apenas 1.400 vídeos subidos desde su creación en 2005 . Khatri et al. (2020) ya constataron una sub-representación de instituciones sanitarias de ámbito internacional al comparar la calidad de la información disponible en YouTube sobre el virus del coronavirus, según el contenido fuera publicado en inglés o en chino mandarín. La constatada asociación en el desempeño de un papel relevante en comunicar la información relativa al brote de una enfermedad, entre el ámbito periodístico y el ámbito sanitario (Lubens, 2015), no se ha producido en el caso de la difusión de contenido sobre la situación de pandemia COVID-19 en España a través de YouTube.

La información epidemiológica que no procede de fuentes gubernamentales se perfila como la temática más significativa entre los vídeos con mayor impacto sobre la situación o evolución en las primeras etapas de la crisis sanitaria en España. En consonancia con investigaciones previas (CostaSánchez y López-García, 2020; Orduña-Malea et al., 2020), las cifras estadísticas o datos numéricos sobre infectados o decesos han sido el recurso informativo más destacado en el consumo de información difundida en YouTube sobre la crisis sanitaria en el territorio español. Tras este tipo de temática, la Comunicación Institucional, es decir, aquella que procede de algunas de las voces autorizadas por el Gobierno español para informar sobre cualquier aspecto relacionado con la pandemia, su incidencia en los distintos ámbitos sociales y/o la gestión de la misma, resulta también recurrente en el consumo que los usuarios de la plataforma de vídeos online han realizado de información relacionada con la pandemia. Destaca el vídeo emitido en directo (y subido posteriormente a esta red social para su posible visionado en diferido) de fragmentos o la cobertura íntegra de las ruedas de prensa ofrecidas diariamente por los portavoces del Comité de Gestión 
Técnica del Coronavirus, algo que Costa-Sánchez y López-García (2020) también evidenciaron en relación a la cobertura periodística de la pandemia en España tanto en medios matriciales, como en nativos digitales, a nivel nacional e internacional.

La alta incidencia de comunicaciones gubernamentales en el consumo de información en las primeras etapas de la crisis sanitaria en España se puede vincular con el efecto "round the flag" (Mueller, 1970). En una situación de riesgo e incertidumbre, el ciudadano encuentra en las figuras de autoridad una fuente de información confiable (López-García, 2020). Los resultados respecto a esta temática discuten los encontrados por Li et al. (2020), en cuyo análisis los vídeos gubernamentales tiene una baja representación. La propuesta de Li et al. (2020) no se circunscribe al territorio español y contiene un sesgo idiomático al atender únicamente a contenidos publicados en inglés, lo que explicaría las discrepancias entre ambas propuestas.

Otras temáticas como la crítica política, la información económica o la jurídica no despiertan el interés de los usuarios de YouTube en relación a la información sobre la situación de la crisis del coronavirus en España en las primeras etapas de la emergencia sanitaria. Si bien, viendo con perspectiva (junio de 2020) la evolución de la situación política y económica generada por la pandemia en España, estás temáticas ocuparían probablemente una posición destacada al analizar el consumo de vídeos en YouTube en fases de la crisis distintas a la inicial. Serán necesarias por tanto investigaciones que den continuidad al punto de partida que propone el presente trabajo.

En relación a la evolución del consumo de vídeos relacionados con la pandemia en España, los resultados resultan similares a los obtenidos por Lázaro-Rodríguez y Herrera-Viedma (2020) y Orduña-Malea et al. (2020), los primeros en relación a noticias publicadas en medios digitales españoles, los segundos sobre vídeos difundidos en YouTube. Se detectan los mayores picos en momentos destacados vinculados a situaciones sanitarias (número de contagios) o decisiones en la gestión política (decreto del Estado de Alarma y prórrogas). Del mismo modo, los hallazgos coinciden con ambos trabajos en un aumento del volumen de publicaciones a raíz del decreto del Estado de Alarma, que se intensifica a finales de marzo para descender progresivamente desde principios de abril. Si bien, Orduña-Malea et al. (2020) detectan un repunte a partir del anuncio de la tercera prórroga (22 abril) y el comienzo del plan de desescalada anunciado el 28 de abril.

Respecto a la comparativa entre los resultados arrojados en función del término de búsqueda empleado (coronavirus o COVID-19) que esta investigación propone como novedad frente a estudios precedentes, se demuestra que dicho término es un factor determinante. Los hallazgos varían considerablemente en función de la etiqueta de búsqueda propuesta. Con los descriptores "coronavirus España" los medios de comunicación nacionales resultan los uploaders mayoritarios, de lo que se desprende que estos optaron por un mayor uso del término "coronavirus" en la definición estratégica de los títulos, descripciones y comentarios de los vídeos que publicaron sobre la situación de la pandemia en España. Algo que ocurre de modo similar en relación a los medios extranjeros pero, en este caso, respecto a las siglas "COVID-19", siendo estos la principal fuente de emisión de contenidos bajo la etiqueta protagonizada por este descriptor. Las temáticas más consumidas también difieren en función del término de búsqueda empleado. Los usuarios que acudieron a YouTube para informarse sobre la situación de la pandemia en España empleando el término "coronavirus" visionaron de forma mayoritaria contenidos centrados en la Comunicación Institucional, mientras que los vídeos que se desprenden del término "COVID-19" giran principalmente en torno a información de índole sanitaria que no procede de fuentes gubernamentales. A falta de investigaciones que contrasten los resultados obtenidos, los datos nos permiten advertir que las siglas "COVID-19" adquieren un matiz más internacional a nivel mediático y se vinculan principalmente al ámbito sanitario, mientras que el vocablo "coronavirus" se configura 
como un término de uso común en el conjunto del sistema mediático español, ligado de forma predominante a la Comunicación Institucional procedente del Gobierno.

En conclusión, este estudio constata la alianza o asociación que ha existido entre YouTube y la industria mediática en cuanto a los contenidos relativos a la pandemia COVID-19. Atendiendo al alto alcance de esta red social, que también se ha constatado al alza desde las primeras etapas de la emergencia sanitaria (C.H. Basch et al., 2020; Khatri et al., 2020; Orduña-Malea et al., 2020), la plataforma de vídeos online evidencia un alto potencial en la transmisión de mensajes que sirvan, no solo para informar sobre la evolución de crisis sanitaria, sino también sobre medidas preventivas ante nuevos contagios o los modos más adecuados de adaptarse a la "nueva normalidad" que impone la pandemia. Esta investigación propone una reflexión sobre la oportunidad que supone para instituciones sanitarias y gubernamentales el uso estratégico de YouTube como medio de difusión masiva, de cara a una gestión más eficaz de la información que estos agentes precisen hacer extensiva a toda la población hasta la finalización de esta "crisis de sombra alargada" (Crespo y Garrido, 2020). Del mismo modo, como ya plantearon Vijaykumar et al. (2018) en relación al uso de Twitter durante el brote del virus Zika, el análisis continuo del flujo comunicativo en esta red social podría servir a las autoridades (sanitarias o gubernamentales) como termómetro de la información que sobre la crisis del coronavirus se está difundiendo y consumiendo, y con ello sobre si la percepción ciudadana de los mensajes institucionales está siendo la adecuada. En este sentido ya apuntan algunos de los estudios precedentes ( $\mathrm{Li}$ et al, 2020) que recomiendan a las agencias de salud pública establecer colaboraciones con canales de noticias o de usuarios influyentes en YouTube para aumentar la adhesión pública a las medidas sanitarias requeridas y a la lucha colectiva contra la pandemia COVID-19.

\section{Bibliografía}

AIMC (Asociación para la Investigación de Medios de Comunicación) (2019). Marco General de los Medios en España 2019. AIMC. Recuperado de https://www.aimc.es/a1mcc0nt3nt/uploads/2019/01/marco19.pdf

AIMC (Asociación para la Investigación de Medios de Comunicación) (2020). AIMC Cuaderno de Bitácora: Semana 4 de Confinamiento (S4C). AIMC. https://www.aimc.es/a1mcc0nt3nt/uploads/2020/04/2020_04_16_NP_AIMC_Cuaderno_de_Bitacora_sem1_s4c.pdf

Antolín-Prieto, R. (2012). Youtube como paradigma del video y la televisión en la web 2.0 [Tesis doctoral]. Universidad Complutense de Madrid.

Basch, C. H., Basch, C. E., Ruggles, K. V. \& Hammond, R. N. (2015). Coverage of the Ebola virus disease epidemic on YouTube. Disaster medicine and public health preparedness, 9(5), 531-535. https://doi.org/10.1017/dmp.2015.77

Basch, C. H., Fung, I. C. H., Hammond, R. N., Blankenship, E. B., Tse, Z. T. H., Fu, K. W., Ip, P. \& Basch, C. E. (2017). Zika virus on YouTube: an analysis of English-language video content by source. Journal of preventive medicine and public health, 50(2), 133-140. https://doi.org/10.3961/jpmph.16.107

Basch, C. H., Hillyer, G. C., Meleo-Erwin, Z. C., Jaime, C., Mohlman, J. \& Basch, C. E. (2020). Preventive behaviors conveyed on YouTube to mitigate transmission of Covid-19: Cross-sectional study. JMIR public health and surveillance, 6(2), e18807. https://doi.org/10.2196/18807 
Basch, C. E., Basch, C. H., Hillyer, G. C. \& Jaime, C. (2020). The Role of YouTube and the Entertainment Industry in Saving Lives by Educating and Mobilizing the Public to Adopt Behaviors for Community Mitigation of COVID-19: Successive Sampling Design Study. JMIR public health and surveillance, 6(2), e19145. https://doi.org/10.2196/19145

Berrocal, S., Campos, E. \& Redondo, M. (2012). Comunicación política en internet: La tendencia al "infoentretenimiento" político en YouTube. Estudios sobre el Mensaje Periodístico, 18(2), 653659. https://doi.org/10.5209/rev_ESMP.2012.v18.n2.41037

Berrocal, S., Campos, E. \& Redondo, M. (2014). Prosumidores mediáticos en la comunicación política, el 'politainment' en YouTube. Comunicar, 12(43), 65-72. http://dx.doi.org/10.3916/C43$\underline{2014-06}$

Berrocal, S., Gil, A. \& Campos, E. (2016). El uso de YouTubeen las elecciones al Parlamento Europeo2014. El caso de España. Comunicacióny Hombre, (12), 57-72. https://doi.org/10.32466/eufv-cyh.2016.12.189.57-72

Berrocal, S., Martín, V. \& Gil, A. (2017). Líderes políticos en YouTube: información y politainmenten las elecciones generales de 2016 (26J) en España. El profesional de la información, 26(5), 937-946. https://doi.org/10.3145/epi.2017.sep.15

Besalú, R. (2020). Pandemia y medios de comunicación convencionales. En: A. Gutiérrez-Rubí \& C. Pont-Sorribes (Coords.). Comunicación política en tiempos de coronavirus (pp. 104-108). Cátedra Ideograma-UPF de Comunicación Política y Democracia.

Bora, K., Das, D., Barman, B. \& Borah, P. (2018). Are internet videos useful sources of information during global public health emergencies? A case study of YouTube videos during the 2015-16 Zika virus pandemic. Pathog Glob Health, 112(6), 320-328. https://doi.org/10.1080/20477724.2018.1507784

Casero-Ripollés, A. (2020). Impact of Covid-19 on the media system. Communicative and democratic consequences of news consumption during the outbreak. El profesional de la información, 29(2), e290223. https://doi.org/10.3145/epi.2020.mar.23

Chadwick, A. (2013). The hybrid media system: Politics and power. Oxford University Press. https://doi.org/10.1093/acprof:oso/9780199759477.001.0001

Crespo, I. \& Garrido, A. (2020). La pandemia del coronavirus: estrategias de comunicación de crisis. Más Poder Local, (41), 12-19. Recuperado de http://maspoderlocal.es/files/articulos/coronavirusestrategias-comunicacion-crisis-mpl41.pdf

Costa-Sánchez, C. \& López-García, X. (2020). Comunicación y crisis del coronavirus en España. Primeras lecciones. El profesional de la información, 29(3), e290304. https://doi.org/10.3145/epi.2020.may.04

De Aguilera, M., Castro, A. \& Pérez-Rufí, J. P. (2018). Between broadcast yourself and broadcast whatever: YouTube's homepage as a synthesis of its business strategy. El profesional de la información, 28(2), e280206. https://doi.org/10.3145/epi.2019.mar.06 
RLCS, Revista Latina de Comunicación Social, 78, 121-153

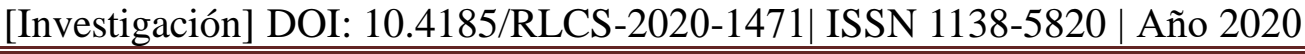

Dubey, D., Amritphale, A., Sawhney, A., Dubey, D. \& Srivastav, N. (2014). Analysis of YouTube as a Source of Information for West Nile Virus Infection. Clinical Medicine \& Research, 12(3-4), 129-132. https://doi.org/10.3121/cmr.2013.1194

España (2020). Real decreto 463/2020, de 14 de marzo, por el que se declara el estado de alarma para la gestión de la situación de crisis sanitaria ocasionada por el Covid-19. Boletín oficial del Estado, (67), 25390-25400. https://www.boe.es/eli/es/rd/2020/03/14/463

Gallardo-Camacho, J. (2010). La televisión tradicional quiere gobernar Internet. El fenómeno Youtube España. Euroeditions.

Gallardo-Paúls, B. \& Enguix-Oliver, S. (2016). Pseudopolítica: el discurso político en las redes sociales. Departamento de Teoría de los Lenguajes y Ciencias de la Comunicación, Universitat de València. Recuperado de http://roderic.uv.es/bitstream/handle/10550/66756/2016.GALLARDOENGUIX_PSEUDOPOLITICA.pdf?sequence=1\&isAllowed $=\mathrm{y}$

Garfin, D. R., Silver, R. C. \& Holman, E. A. (2020). The novel coronavirus (Covid-2019) outbreak: Amplification of public health consequences by media exposure. Health psychology, 39(5), 355357. https://doi.org/10.1037/hea0000875

Gil, M. (2019a). El uso de YouTube en el Procés Catalán. Comunicación Política a través de los Social Media: ¿Prosumidores Mediatizados?. Estudios sobre el Mensaje Periodístico, 25(1), 213234. https://doi.org/10.5209/ESMP.63725

Gil, M. (2019b). ¿Participa la esfera política en YouTube? Producción y consumo de información en la campaña electoral catalana de 2017. Ámbitos, Revista Internacional de Comunicación, (44), 141-161. https://doi.org/10.12795/Ambitos.2019.i44.09

Gil, M. \& Gómez de Travesedo, R. (2020). Gestión de la política española en YouTube. Una asignatura pendiente. Revista Observatorio $\left(O B S^{*}\right), \quad 14(1), \quad 22-44$. https://doi.org/10.15847/obsOBS14120201491

Gil, M., Gómez de Travesedo, R. \& Almansa, A. (2019). Politainment y personalización política. ¿De la televisión a YouTube?. Revista Latina de Comunicación Social, (74), 1542-1564. https://doi.org/10.4185/RLCS-2019-1398

Idoiaga-Mondragón, N. (2016). Redes sociales en tiempos de riesgo: Analizando el ébola mediante Twitter. Opción: Revista de ciencias humanas y sociales, 32(11), 740-756. Recuperado de https://produccioncientificaluz.org/index.php/opcion/article/view/21979

Khatri, P., Singh, S. R., Belani, N. K., Yeong, Y. L., Lohan, R., Lim, Y. W. \& Teo, W. Z. Y. (2020). YouTube as source of information on 2019 novel coronavirus outbreak: a cross sectional study of English and Mandarin content. Travel medicine and infectious disease, 35, e101636. https://doi.org/10.1016/j.tmaid.2020.101636

Lázaro-Rodríguez, P. \& Herrera-Viedma, E. (2020). Noticias sobre Covid-19 y 2019-nCoV en medios de comunicación de España: el papel de los medios digitales en tiempos de confinamiento. El profesional de la información, 29(3), e290302. https://doi.org/10.3145/epi.2020.may.02 
Li, H. O. Y., Bailey, A., Huynh, D. \& Chan, J. (2020). YouTube as a source of information on COVID-19: a pandemic of misinformation? BMJ Global Health, 5(5), e002604. http://dx.doi.org/10.1136/bmjgh-2020-002604

López-García, G. (2020). Vigilar y castigar: el papel de militares, policías y guardias civiles en la comunicación de la crisis del Covid-19 en España. El profesional de la información, 29(3), e290311. https://doi.org/10.3145/epi.2020.may.11

López-Meri, A., Marcos-García, S. \& Casero-Ripollés, A. (2017). What do politicians do on Twitter? Functions and communication strategies in the Spanish electoral campaign of 2016. El profesional de la Información, 26(5), 795-804. https://doi.org/10.3145/epi.2017.sep.02

Lopezosa, C., Orduña-Malea, E. \& Pérez-Montoro, M. (2019). Making video news visible: Identifying the optimization strategies of the cybermedia on YouTube using web metrics. Journalism practice, 4(4), 465-482. https://doi.org/10.1080/17512786.2019.1628657

Lubens, P. (2015). Journalists and public health professionals: Challenges of a symbiotic relationship. Disaster medicine and public health preparedness, 9(1), 59-63. https://doi.org/10.1017/dmp.2014.127

Masip, P., Aran-Ramspott, S., Ruiz-Caballero, C., Suau, J., Almenar, E. \& Puertas-Graell, D. (2020). Consumo informativo y cobertura mediática durante el confinamiento por el Covid-19: sobreinformación, sesgo ideológico y sensacionalismo. El profesional de la información, 29(3), e290312. https://doi.org/10.3145/epi.2020.may.12

Masip, P., Ruiz-Caballero, C. \& Suau, J. (2019). Active audiences and social discussion on the digital public sphere. Review article. El profesional de la información, 28(2), e280204. https://doi.org//10.3145/epi.2019.mar.04

Mueller, J. (1970). Presidential popularity from Truman to Johnson. American political science review, 64(1), 18-34. https://doi.org/10.2307/1955610

Murolo, N. L. (2010). Post-zapping: transmite tú mismo. YouTube como la televisión pos-moderna. Razón y Palabra, (71). Recuperado de http://www.razonypalabra.org.mx/N/N71/VARIA/14\%20MUROLO-REVISADO.pdf

Nagpal, S. J. S., Karimianpour, A., Mukhija, D., Mohan, D. \& Brateanu, A. (2015). YouTube Videos as a Source of Medical Information During the Ebola Hemorrhagic Fever Epidemic. SpringerPlus, 4: 457. https://doi.org/10.1186/s40064-015-1251-9

Orduña-Malea, E., Font-Julián, C. I. \& Ontalba-Ruipérez, J. A. (2020). Covid-19: análisis métrico de vídeos y canales de comunicación en YouTube. El profesional de la información, 29(4), e290401. https://doi.org/10.3145/epi.2020.jul.01

Pandey, A., Patni, N., Singh, M., Sood, A. \& Singh, G. (2010). YouTube as a source of information on the H1N1 influenza pandemic. American journal of preventive medicine, 38(3), e1-e3. https://doi.org/10.1016/j.amepre.2009.11.007 
RLCS, Revista Latina de Comunicación Social, 78, 121-153

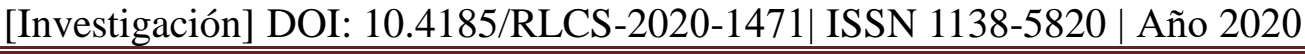

Park, S., Boatwright, B. \& Johnson, E. (2019). Information channel preference in health crisis: Exploring the roles of perceived risk, preparedness, knowledge, and intent to follow directives. Public relations review, 45(5). https://doi.org/10.1016/j.pubrev.2019.05.015

Pathak, R., Poudel, D. R., Karmacharya, P., Pathak, A., Aryal, M. R., Mahmood, M. \& Donato, A. A. (2015). YouTube as a source of information on Ebola virus disease. North American journal of medical sciences, 7(7), 306-309. https://doi.org/10.4103/1947-2714.161244

Pérez-Rufi, J. P. (2012). La actualidad en Youtube: claves de los videos más vistos durante un mes. Global Media Journal, 9(17), 44-62. Recuperado de https://biblat.unam.mx/hevila/Globalmediajournalenespanol/2012/vol9/no17/4.pdf

Rodríguez-Serrano, A., García-Catalán, S. \& Martín-Núñez, M. (2019). Estrategias narrativas audiovisuales de desinformación en YouTube de la nueva extrema derecha europea. El Profesional de la Información, 28(3), e280311. https://doi.org/10.3145/epi.2019.may.11

Rojo-Martínez, J. M. \& Soler-Contreras, A. (2020). Comunicación política en tiempos de alarma: el caso español. Más Poder Local, (41), 12-19. Recuperado de http://maspoderlocal.es/files/articulos/espana-comunicacion-alarma-sanitaria-mpl41.pdf

Takahashi, B., Tandoc, E. C. \& Carmichael, C. (2015). Communicating on Twitter during a disaster: An analysis of tweets during Typhoon Haiyan in the Philippines. Computers in human behavior, (50), 392-398. https://doi.org/10.1016/j.chb.2015.04.020

Uribe-Jongbloed, E. (2016). El cambio mediático de la televisión: Netflix y la televisión en teléfonos inteligentes. Palabra Clave, 19(2), 358-364. https://doi.org/10.5294/pacla.2016.19.2.1

Vijaykumar, S., Nowak, G., Himelboim, I. \& Jin, Y. (2018). Virtual Zika transmission after the first U.S. case: Who said what and how it spread on Twitter. American journal of infection control, 46(5), 549-557. https://doi.org/10.1016/j.ajic.2017.10.015

Walton, L. R., Seitz, H. H. \& Ragsdale, K. (2012). Strategic use of YouTube during a national public health crisis: the CDC's response to the $2009 \mathrm{H} 1 \mathrm{~N} 1$ flu epidemic. Case studies in strategic communication, 1(3), 25-37. https://doi.org/10.1123/ijsc.4.1.99

Westlund, O. \& Ghersetti, M. (2015). Modelling news media use. Positing and applying the GC/MC model to the analysis of media use in everyday life and crisis situations. Journalism studies, 16(2), 133-151. https://doi.org/10.1080/1461670X.2013.868139

WHO (World Health Organization) (2020). WHO Director-General's opening remarks at the media briefing on COVID-19 - 11 March 2020. https://www.who.int/dg/speeches/detail/who-directorgeneral-s-opening-remarks-at-the-media-briefing-on-covid-19---11-march-2020

Xifra, J. (2020). Comunicación corporativa, relaciones públicas y gestión del riesgo reputacional en tiempos del Covid-19. El profesional de la información, 29(2), e290220. https://doi.org/10.3145/epi.2020.mar.20 


\section{AUTOR/ES:}

\section{Marta Gil Ramírez.}

Doctora en Comunicación Audiovisual y Master en Comunicación y Cultura por la Universidad de Málaga. Miembro del grupo de investigación PAIDI Comunicación y Poder, adscrito a dicha universidad. Docente del Departamento de Comunicación Audiovisual y Publicidad de la Universidad de Málaga. Autora del libro Irrupción de Podemos y Ciudadanos en el panorama político español. Framing televisivo de la comunicación política de campaña. Sus líneas de investigación están centradas en comunicación política, género y cambio social, temáticas que centran diversas publicaciones en acreditadas revistas científicas y editoriales.

martagr@uma.es

\section{Índice H: 2}

Orcid ID: https://orcid.org/0000-0002-0577-5628

Google Scholar: https://scholar.google.com/citations?hl=es\&user=EauloSgAAAAJ

ResearchGate: https://www.researchgate.net/profile/Marta_Gil_Ramirez

Dialnet: $\underline{\text { https://dialnet.unirioja.es/servlet/autor?codigo }=4850817}$

\section{Ruth Gómez de Travesedo Rojas.}

Profesora en el Departamento de Comunicación Audiovisual y Publicidad de la Universidad de Málaga desde 2009. Premio Extraordinario de Doctorado Interuniversitario en Comunicación. Investigadora en el Proyecto Nacional I+D+I: CSO2016-79357-R Lobby y Comunicación en España. Análisis de estrategias de comunicación financiado por el Ministerio de Economía, Industria y Competitividad. Sus líneas de investigación están relacionadas con la comunicación de género, comunicación política, comunicación social y la publicidad y relaciones públicas, con varias publicaciones en capítulos de libros y revistas de reconocida relevancia en el ámbito académico.

ruthgtr@uma.es

Índice H: 4

Orcid ID: https://orcid.org/0000-0003-4452-5928

Google Scholar: https://scholar.google.com/citations?user=ZznyWGwAAAAJ

ResearchGate: https://www.researchgate.net/profile/Ruth_Gomez_De_Travesedo_Rojas

Scopus ID: https://www.scopus.com/authid/detail.uri?authorId=57191893692

Dialnet: https://dialnet.unirioja.es/servlet/autor?codigo=4105428

\section{Ana Almansa Martínez.}

Profesora Titular de Universidad, en el Departamento de Comunicación Audiovisual y Publicidad, Universidad de Málaga (España). Autora de libros como Del gabinete de prensa al gabinete de comunicación, Nuevos medios en Comunicación Política, Assessorías de Comunicaçao y de más de cincuenta artículos en revistas científicas. Investigadora principal en el proyecto de investigación Lobby y Comunicación en España (Programa Nacional de I+D), La Comunicación de los bienes patrimoniales para el desarrollo económico y social de Andalucía (Centro de Estudios Andaluces) y del proyecto Observatorio de los Gabinetes de Comunicación en Andalucía (Proyecto de Excelencia). Directora de 25 tesis doctorales ya defendidas. Editora de la Revista Internacional de Relaciones Públicas. Coordinadora del Máster Oficial Dirección Estratégica e Innovación en Comunicación.

anaalmansa@uma.es

\section{Índice H: 15}

Orcid ID: https://orcid.org/0000-0003-0256-6369

Google Scholar: https://scholar.google.com/citations?hl=es\&user=Q8LWr1AAAAAJ

ResearchGate: https://www.researchgate.net/profile/Ana_Almansa_Martinez

Scopus ID: $\underline{\text { https: } / / \text { www.scopus.com/authid/detail.uri?authorId }=55618972400}$

Dialnet: https://dialnet.unirioja.es/servlet/autor?codigo $=339858$ 


\section{Anexos}

Anexo 1: Desglose sobre la tipología de uploaders referida a medios de comunicación y usuarios comunes en función de la etiqueta de búsqueda empleada ("coronavirus España" o "COVID-19 España”).

\begin{tabular}{|c|c|c|c|c|}
\hline \multicolumn{5}{|c|}{ MEDIOS DE COMUNICACIÓN } \\
\hline \multicolumn{5}{|c|}{ TÉRMINO DE BÚSQUEDA EMPLEADO: CORONAVIRUS ESPAÑA } \\
\hline Ubicaciór & geográfica del medio & $\begin{array}{l}\text { Denominación del } \\
\text { canal en YouTube }\end{array}$ & Idioma de publicación & $\begin{array}{c}\% \text { de contenidos } \\
\text { publicados respecto a la } \\
\text { muestra global de la } \\
\text { etiqueta }\end{array}$ \\
\hline \multirow{7}{*}{\multicolumn{2}{|c|}{ España }} & EL PAIS & español & $17 \%$ \\
\hline & & El Mundo & español & $5 \%$ \\
\hline & & $\frac{\text { RTVE Noticias / }}{\text { RTVE }}$ & español & $2 \%$ \\
\hline & & La Vanguardia & español & $18 \%$ \\
\hline & & Cadena SER & español & $4 \%$ \\
\hline & & AGENCIA EFE & español & $2 \%$ \\
\hline & & LibertadDigital & español & $4 \%$ \\
\hline & & & & TOTAL: $52 \%$ \\
\hline \multirow{6}{*}{\multicolumn{2}{|c|}{ Reino Unido }} & DW News & inglés & $6 \%$ \\
\hline & & $\frac{\text { Sky News } / \text { Sky News }}{\text { en Español }}$ & inglés /español & $4 \%$ \\
\hline & & BBC News & inglés & $6 \%$ \\
\hline & & ITV News & inglés & $2 \%$ \\
\hline & & On Demand News & inglés & $1 \%$ \\
\hline & & Reuters & inglés & $1 \%$ \\
\hline \multirow{14}{*}{ Extranjero } & China & $\frac{\text { South China Morning }}{\text { Post }}$ & inglés & $2 \%$ \\
\hline & Colombia & Noticias Caracol & español & $1 \%$ \\
\hline & Perú & 24 Horas & español & $1 \%$ \\
\hline & Argentina & $\frac{\text { Televisión Pública }}{\text { Noticias }}$ & español & $1 \%$ \\
\hline & México & MILENIO & español & $1 \%$ \\
\hline & \multirow{9}{*}{ EE. UU. } & Noticias Telemundo & español & $1 \%$ \\
\hline & & Global News & inglés & $1 \%$ \\
\hline & & La Nación Costa Rica & español & $2 \%$ \\
\hline & & $\frac{\text { Bloomberg Markets }}{\text { and Finance }}$ & inglés & $2 \%$ \\
\hline & & VICE News & inglés & $1 \%$ \\
\hline & & VOA News & inglés & $1 \%$ \\
\hline & & $\frac{\text { CBS This Morning }}{\text { (Programa) }}$ & inglés & $2 \%$ \\
\hline & & $\begin{array}{c}\frac{\text { Good Morning }}{\text { America }} \\
(\text { Programa })\end{array}$ & inglés & $1 \%$ \\
\hline & & $\frac{\text { Al Rojo Vivo }}{\text { (Programa) }}$ & español & $1 \%$ \\
\hline
\end{tabular}

\section{TÉRMINO DE BÚSQUEDA EMPLEADO: COVID-19 ESPAÑA}

Ubicación geográfica del medio
Denominación del canal en YouTube
Idioma de publicación
TOTAL: $38 \%$

$\%$ de contenidos publicados respecto a la muestra global de la etiqueta 
RLCS, Revista Latina de Comunicación Social, 78, 121-153

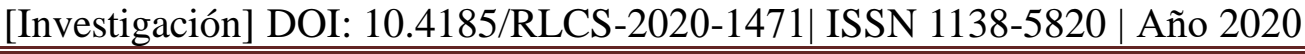

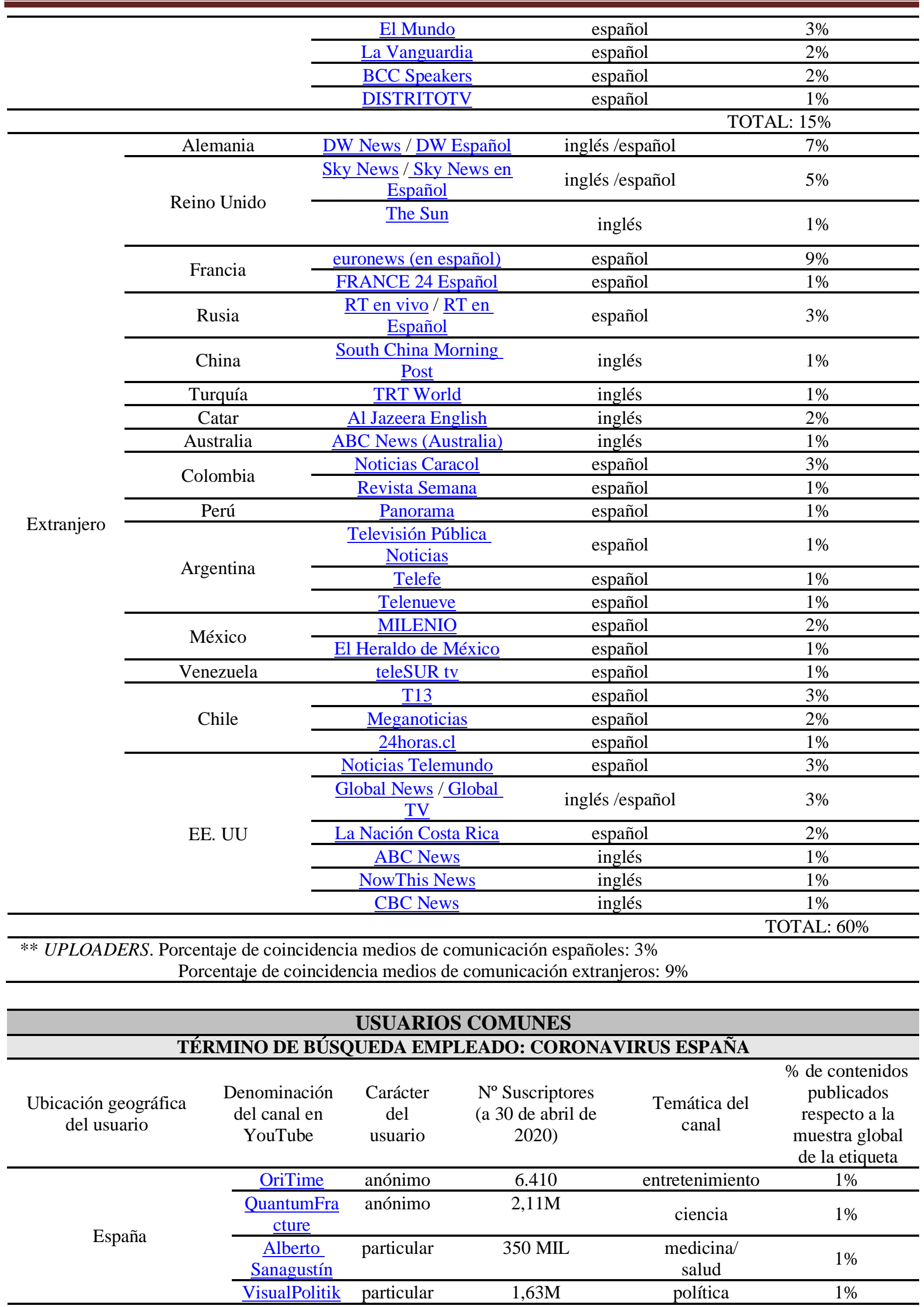


RLCS, Revista Latina de Comunicación Social, 78, 121-153

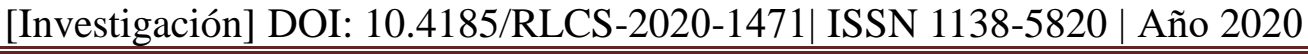

\begin{tabular}{|c|c|c|c|c|c|c|}
\hline & & & \multirow[b]{2}{*}{ anónimo } & \multirow[b]{2}{*}{$808 \mathrm{MIL}$} & & TOTAL: $4 \%$ \\
\hline \multirow{2}{*}{$\begin{array}{l}\text { Extranjer } \\
\text { o }\end{array}$} & \multirow{2}{*}{ México } & $\underline{\text { Platzi }}$ & & & $\begin{array}{c}\text { educación en } \\
\text { línea }\end{array}$ & $1 \%$ \\
\hline & & \multirow[t]{2}{*}{$\frac{\text { concienciara }}{\underline{\text { dio }}}$} & anónimo & $1,1 \mathrm{M}$ & $\begin{array}{l}\text { periodismo } \\
\text { amateur }\end{array}$ & $1 \%$ \\
\hline & & & \multirow[b]{2}{*}{ anónimo } & & & TOTAL: $2 \%$ \\
\hline \multirow[t]{2}{*}{ Otros } & No consta & \multirow[t]{2}{*}{$\underline{\text { Ramonsoo }}$} & & \multirow[t]{2}{*}{1.700} & no definido & \multirow{2}{*}{$\frac{2 \%}{\text { TOTAL: } 2 \%}$} \\
\hline & & & & & & \\
\hline \multicolumn{7}{|c|}{ TÉRMINO DE BÚSQUEDA EMPLEADO: COVID-19 ESPAÑA } \\
\hline \multicolumn{2}{|c|}{$\begin{array}{l}\text { Ubicación geográfica del } \\
\text { usuario }\end{array}$} & $\begin{array}{l}\text { Denominación } \\
\text { del canal en } \\
\text { YouTube }\end{array}$ & $\begin{array}{l}\text { Carácte } \\
\text { r del } \\
\text { usuario }\end{array}$ & $\begin{array}{c}N^{\circ} \text { Suscriptores } \\
\text { (a } 30 \text { de abril de } \\
\text { 2020) }\end{array}$ & $\begin{array}{l}\text { Temática del } \\
\text { canal }\end{array}$ & $\begin{array}{c}\% \text { de contenidos } \\
\text { publicados } \\
\text { respecto a la } \\
\text { muestra global } \\
\text { de la etiqueta }\end{array}$ \\
\hline \multirow{7}{*}{\multicolumn{2}{|c|}{ España }} & GlóbuloAzul & $\begin{array}{c}\text { anónim } \\
\text { o }\end{array}$ & $236 \mathrm{MIL}$ & salud & $1 \%$ \\
\hline & & $\underline{\text { Sese195 }}$ & $\begin{array}{c}\text { anónim } \\
\text { o } \\
\end{array}$ & 2.680 & música & $1 \%$ \\
\hline & & $\underline{\text { unProfesor }}$ & $\begin{array}{c}\text { anónim } \\
\text { o }\end{array}$ & $937 \mathrm{MIL}$ & educación & $1 \%$ \\
\hline & & $\underline{\text { Marcel Garcia }}$ & $\begin{array}{c}\text { particul } \\
\text { ar }\end{array}$ & 58.300 & no definido & $2 \%$ \\
\hline & & $\underline{\text { VisualPolitik }}$ & $\begin{array}{l}\text { particul } \\
\text { ar }\end{array}$ & $1,63 \mathrm{M}$ & política & $1 \%$ \\
\hline & & $\underline{\text { Alberto }}$ & $\begin{array}{c}\text { particul } \\
\text { ar }\end{array}$ & $350 \mathrm{MIL}$ & $\begin{array}{l}\text { medicina/ } \\
\text { salud }\end{array}$ & $1 \%$ \\
\hline & & $\begin{array}{l}\text { César para } \\
\text { Jesucristo } \\
\end{array}$ & $\begin{array}{c}\text { particul } \\
\text { ar } \\
\end{array}$ & 44.900 & religión & $1 \%$ \\
\hline & & & & & & TOTAL: $8 \%$ \\
\hline \multirow{7}{*}{$\begin{array}{l}\text { Extranjer } \\
\quad \text { o }\end{array}$} & Corea del Sur & $\frac{\text { Asian Boss }}{\text { Español }}$ & $\begin{array}{c}\text { anónim } \\
\text { o }\end{array}$ & $574 \mathrm{MIL}$ & $\begin{array}{l}\text { periodismo } \\
\text { amateur }\end{array}$ & $1 \%$ \\
\hline & Bolivia & $\frac{\text { El Maestro Te }}{\text { Enseña }}$ & $\begin{array}{c}\text { anónim } \\
\text { o }\end{array}$ & $100 \mathrm{MIL}$ & no definido & $1 \%$ \\
\hline & Argentina & $\frac{\text { El Traductor de }}{\underline{\text { Ingeniería }}}$ & $\begin{array}{c}\text { particul } \\
\text { ar }\end{array}$ & $403 \mathrm{MIL}$ & educación & $1 \%$ \\
\hline & \multirow{2}{*}{ México } & Doctor Vic & $\begin{array}{l}\text { particul } \\
\text { ar }\end{array}$ & $1,74 \mathrm{M}$ & $\begin{array}{c}\text { medicina/ } \\
\text { salud }\end{array}$ & $1 \%$ \\
\hline & & $\underline{\text { math} 2 \mathrm{me}}$ & $\begin{array}{c}\text { anónim } \\
\text { o } \\
\end{array}$ & $1,97 \mathrm{M}$ & educación & $1 \%$ \\
\hline & Colombia & $\underline{\text { Luis Campos }}$ & $\begin{array}{l}\text { particul } \\
\text { ar }\end{array}$ & 30.400 & música & $1 \%$ \\
\hline & \multirow[t]{2}{*}{ EE.UU. } & dj show & $\begin{array}{c}\text { anónim } \\
\text { o } \\
\end{array}$ & 28.300 & música & $1 \%$ \\
\hline \multirow{3}{*}{ Otros } & & & & & & TOTAL: $7 \%$ \\
\hline & \multirow[t]{2}{*}{ No consta } & $\frac{\frac{\text { VIRTUOSSO.C }}{\mathrm{OM}}}{\underline{\mathrm{O}}}$ & $\begin{array}{c}\text { anónim } \\
\text { o }\end{array}$ & 399 MIL & $\begin{array}{c}\text { cursos música } \\
\text { online }\end{array}$ & $1 \%$ \\
\hline & & & & $\begin{array}{c}\text { TOTAL: } \\
\text { (más de) } 3,9 \mathrm{M} \\
\end{array}$ & & TOTAL: $1 \%$ \\
\hline \multicolumn{7}{|c|}{$\begin{array}{l}\text { ** UPLOADERS. Porcentaje de coincidencia usuarios comunes españoles: } 2 \% \\
\text { Porcentaje de coincidencia usuarios comunes extranjeros: } 0 \% \\
\text { **MEDIA SUPCRIPTORES (eliminando duplicaciones): } 199.412 \\
\text { ** Tres rangos (20 emisores usuarios comunes una vez eliminadas duplicaciones): } \\
\text { menos de 100MIL: } 35 \% \\
\text { entre 100MIL y 1M: } 40 \% \\
\text { más de 1M: } 25 \%\end{array}$} \\
\hline
\end{tabular}


RLCS, Revista Latina de Comunicación Social, 78, 121-153

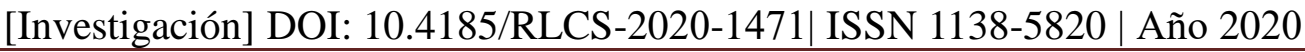

Anexo 2: Desglose sobre la temática de los contenidos en función de la etiqueta de búsqueda empleada ("coronavirus España" o "COVID-19 España").

\begin{tabular}{|c|c|c|c|c|}
\hline & & $\begin{array}{l}\text { ETIQUETA: } \\
\text { CORONAVIRUS } \\
\text { ESPAÑA }\end{array}$ & $\begin{array}{c}\text { ETIQUETA: } \\
\text { COVID-19 } \\
\text { ESPAÑA }\end{array}$ & $\begin{array}{c}\text { COMBINACIÓN AMBAS } \\
\text { ETIQUETAS }\end{array}$ \\
\hline TEMÁTICA & SUBCATEGORÍA TEMÁTICA & $\begin{array}{c}\text { \% respecto a la } \\
\text { muestra total de la } \\
\text { etiqueta }\end{array}$ & $\begin{array}{c}\% \text { respecto a la } \\
\text { muestra total de } \\
\text { la etiqueta }\end{array}$ & $\%$ GLOBAL \\
\hline \multirow{3}{*}{$\begin{array}{l}\text { Información } \\
\text { de índole } \\
\text { sanitaria }\end{array}$} & Información Epidemiológica & $26,00 \%$ & $29,59 \%$ & $55,59 \%$ \\
\hline & Testimonios & $6,00 \%$ & $8,17 \%$ & $14,17 \%$ \\
\hline & $\begin{array}{l}\text { Investigación } \\
\text { vacuna }\end{array}$ tratamientos $\mathrm{y} / \mathrm{o}$ & $2,00 \%$ & $6,12 \%$ & $8,12 \%$ \\
\hline \multirow[t]{4}{*}{$\begin{array}{l}\text { Comunicación } \\
\text { institucional }\end{array}$} & $\begin{array}{l}\text { Fragmento rueda de prensa Comité } \\
\text { de Gestión Técnica: exclusivamente } \\
\text { datos epidemiológicos }\end{array}$ & $15,00 \%$ & $4,08 \%$ & $19,08 \%$ \\
\hline & $\begin{array}{l}\text { Rueda de prensa íntegra del Comité } \\
\text { de Gestión Técnica }\end{array}$ & $16,00 \%$ & $2,04 \%$ & $18,04 \%$ \\
\hline & $\begin{array}{l}\text { Comparecencias del Presidente del } \\
\text { Gobierno }\end{array}$ & $3,00 \%$ & $2,04 \%$ & $5,04 \%$ \\
\hline & Otros (Comunicación institucional) & $2,00 \%$ & $1,02 \%$ & $3,02 \%$ \\
\hline \multicolumn{2}{|l|}{ Crítica política } & $4,00 \%$ & $8,17 \%$ & $12,17 \%$ \\
\hline \multicolumn{2}{|c|}{ Medidas restrictivas y/o sanciones } & $5,00 \%$ & $4,08 \%$ & $9,08 \%$ \\
\hline \multicolumn{2}{|c|}{ Información económica } & $0 \%$ & $3,06 \%$ & $3,06 \%$ \\
\hline \multicolumn{2}{|c|}{ Información jurídica } & $0 \%$ & $0 \%$ & $0 \%$ \\
\hline \multirow{3}{*}{$\begin{array}{l}\text { Combinación } \\
\text { información } \\
\text { sanitaria con } \\
\text { otras temáticas }\end{array}$} & $\begin{array}{l}\text { Información sanitaria }+ \text { medidas } \\
\text { restrictivas y/o sanciones }\end{array}$ & $6,00 \%$ & $7,15 \%$ & $13,15 \%$ \\
\hline & $\begin{array}{l}\text { Información sanitaria }+ \text { crítica } \\
\text { política }\end{array}$ & $1,00 \%$ & $3,06 \%$ & $4,06 \%$ \\
\hline & $\begin{array}{l}\text { Información sanitaria + información } \\
\text { económica }\end{array}$ & $0 \%$ & $2,04 \%$ & $2,04 \%$ \\
\hline \multicolumn{2}{|c|}{$\begin{array}{l}\text { Programas de larga duración que abordan más de } \\
\text { dos temáticas }\end{array}$} & $6,00 \%$ & $10,20 \%$ & $16,20 \%$ \\
\hline \multirow{2}{*}{\multicolumn{2}{|c|}{ Otros global }} & $8,00 \%$ & $9,18 \%$ & $17,18 \%$ \\
\hline & & TOTAL: $100 \%$ & TOTAL: $100 \%$ & TOTAL: $200 \%$ \\
\hline
\end{tabular}

Anexo 3: Desglose sobre el cruce "uploaders/temática" en función de la etiqueta de búsqueda empleada ("coronavirus España" o "COVID-19 España").

\begin{tabular}{|c|c|c|c|c|c|c|c|c|c|c|c|}
\hline & & & & & & & & & & & \\
\hline & & \multicolumn{10}{|c|}{ TIPOLOGÍA EMISOR } \\
\hline & & \multicolumn{4}{|c|}{ Medio de comunicación } & \multirow{2}{*}{\multicolumn{2}{|c|}{$\begin{array}{l}\text { Usuario } \\
\text { común }\end{array}$}} & \multirow{2}{*}{\multicolumn{2}{|c|}{$\begin{array}{l}\text { Partido } \\
\text { Político }\end{array}$}} & \multirow{2}{*}{\multicolumn{2}{|c|}{ Otros }} \\
\hline & & \multicolumn{2}{|c|}{ Español } & \multicolumn{2}{|c|}{ Extranjero } & & & & & & \\
\hline & & $\begin{array}{c}\text { COR. } \\
*\end{array}$ & COV. & $\begin{array}{c}\text { COR. } \\
*\end{array}$ & $\begin{array}{c}\text { COV. } \\
* * *\end{array}$ & $\begin{array}{c}\text { COR. } \\
*\end{array}$ & $\begin{array}{c}\text { COV. } \\
* *\end{array}$ & $\begin{array}{c}\text { COR. } \\
*\end{array}$ & $\begin{array}{c}\text { COV. } \\
* * *\end{array}$ & $\begin{array}{c}\text { COR. } \\
*\end{array}$ & $\underset{* *}{\mathrm{COV} .}$ \\
\hline TEMÁTICA & SUBCATEGORÍA TEMÁTICA & & & & & & & & & & \\
\hline \multirow{3}{*}{$\begin{array}{l}\text { Información } \\
\text { de índole } \\
\text { sanitaria }\end{array}$} & Información Epidemiológica & $3,00 \%$ & $2,04 \%$ & $22,00 \%$ & $24,49 \%$ & $1,00 \%$ & $3,06 \%$ & & & & \\
\hline & Testimonios & $2,00 \%$ & & $4,00 \%$ & $5,10 \%$ & & $3,07 \%$ & & & & \\
\hline & Investigación tratamientos y/o vacuna & $1,00 \%$ & $1,02 \%$ & & $3,06 \%$ & $1,00 \%$ & $2,04 \%$ & & & & \\
\hline \multirow[t]{4}{*}{$\begin{array}{l}\text { Comunicación } \\
\text { institucional }\end{array}$} & $\begin{array}{l}\text { Fragmento rueda de prensa Comité de } \\
\text { Gestión Técnica: exclusivamente datos } \\
\text { epidemiológicos }\end{array}$ & $15,00 \%$ & $3,06 \%$ & & $1,02 \%$ & & & & & & \\
\hline & $\begin{array}{l}\text { Rueda de prensa íntegra del Comité de } \\
\text { Gestión Técnica }\end{array}$ & $16,00 \%$ & $2,04 \%$ & & & & & & & & \\
\hline & $\begin{array}{l}\text { Comparecencias del Presidente } \\
\text { Gobierno }\end{array}$ & $3,00 \%$ & $2,04 \%$ & & & & & & & & \\
\hline & Otros (Comunicación Institucional) & $2,00 \%$ & $1,02 \%$ & & & & & & & & \\
\hline \multicolumn{2}{|l|}{ Crítica política } & $1,00 \%$ & $1,02 \%$ & & $1,02 \%$ & $2,00 \%$ & $3,07 \%$ & $1,00 \%$ & $2,04 \%$ & & $1,02 \%$ \\
\hline \multicolumn{2}{|c|}{ Medidas restrictivas y/o sanciones } & $1,00 \%$ & & $4,00 \%$ & $4,08 \%$ & & & & & & \\
\hline \multicolumn{2}{|c|}{ Información económica } & & $2,04 \%$ & & $1,02 \%$ & & & & & & \\
\hline \multicolumn{12}{|c|}{ Información jurídica } \\
\hline \multirow{3}{*}{$\begin{array}{l}\text { Combinación } \\
\text { información } \\
\text { sanitaria con } \\
\text { otras temáticas }\end{array}$} & $\begin{array}{l}\begin{array}{l}\text { Información sanitaria }+ \text { medidas } \\
\text { restrictivas y/o sanciones }\end{array} \\
\text { res }\end{array}$ & $1,00 \%$ & & $5,00 \%$ & $7,15 \%$ & & & & & & \\
\hline & Información sanitaria + crítica política & & $1,02 \%$ & & $1,02 \%$ & $1,00 \%$ & $1,02 \%$ & & & & \\
\hline & $\begin{array}{l}\text { Información sanitaria + información } \\
\text { económica }\end{array}$ & & & & $2,04 \%$ & & & & & & $3,06 \%$ \\
\hline
\end{tabular}


RLCS, Revista Latina de Comunicación Social, 78, 121-153

[Investigación] DOI: 10.4185/RLCS-2020-1471| ISSN 1138-5820 | Año 2020

\begin{tabular}{l|c|c|c|c|c|c|c|c|c|c}
\hline \hline $\begin{array}{l}\text { Programas de larga duración que abordan más de dos } \\
\text { temáticas }\end{array}$ & $5,00 \%$ & & $1,00 \%$ & $7,14 \%$ & & & & & & \\
\hline Otros global & $2,00 \%$ & & $2,00 \%$ & $3,06 \%$ & $3,00 \%$ & $4,08 \%$ & & & $1,00 \%$ & $2,04 \%$ \\
\hline TOTALES & $52,00 \%$ & $15,30 \%$ & $38,00 \%$ & $60,20 \%$ & $8,00 \%$ & $16,34 \%$ & $1,00 \%$ & $2,04 \%$ & $1,00 \%$ & $6,12 \%$ \\
\hline *Etiqueta "coronavirus España" \\
** Etiqueta "COVID-19 España"
\end{tabular}

